\title{
STRUCTURAL BEHAVIOUR OF OVAL HOLLOW SECTIONS
}

\author{
L. Gardner \\ Department of Civil and Environmental Engineering, Imperial College London
}

Email: leroy.gardner@imperial.ac.uk

\begin{abstract}
Structural oval hollow sections represent a recent and rare addition to the range of cross-sections available to structural engineers and architects. Their emergence is also timely given the increasing application of hollow sections in construction and the current trend towards the use of bare steelwork to express structural form. However, despite widespread interest in their application on the basis of both architectural appeal and structural efficiency, a lack of verified design guidance is inhibiting uptake. This paper summarises previous analytical and experimental studies on oval hollow sections, and describes laboratory testing, numerical modelling and evaluation of preliminary design rules for the recently introduced structural elliptical hollow sections. Laboratory testing has been carried out in two primary structural configurations - compression and in-plane bending. In addition to the basic geometry (including initial geometric imperfections) and material properties, full load-deformation histories were recorded. Numerical models, using the finite element package ABAQUS, were created and validated against the test results, before a series of sensitivity and parametric studies were conducted. The models included features such as curved geometry, non-linear material properties and initial geometric imperfections. For stub column behaviour, ultimate load was generally well predicted by the numerical models, but prediction of deformation at ultimate load was less accurate. For bending behaviour, the full bending moment-deformation history was consistently well predicted. Comparison of the test and finite element results against preliminary design rules has demonstrated broadly acceptable agreement, but additional analysis on the basis of further testing and modelling is required.
\end{abstract}

Keywords: ABAQUS, elliptical, hollow sections, laboratory testing, numerical modelling, oval, steel structures.

\section{INTRODUCTION}

As the construction industry continues to evolve, innovative products and design techniques are being developed to respond to the ever increasing demands on both the efficiency and aesthetics of civil engineering structures. A recent advance has been the introduction of high strength, hot-rolled and cold-formed oval hollow sections for structural application. The fundamental test data and verified structural design guidance to enable their safe and efficient use is currently being developed. Previously, in projects where oval sections have been specified, structural engineers have been forced to adopt a pragmatic and conservative approach to the design [1]. A number of examples of applications of oval hollow sections in structural engineering projects have been reported [2].

Whilst maintaining, if not exceeding the aesthetic appeal of circular sections, oval sections also offer the structural advantages of sections with differing major and minor axis properties, i.e. more efficient use of material in a number of primary structural configurations, for example, flexural elements (in major axis bending) and compression elements (braced against minor axis buckling).

An oval has no single mathematical definition, but may be described generally as a curve with a smooth, convex, closed 'egg-like' shape; many types of oval, with a range of geometric properties (degree of elongation, asymmetry etc) therefore exist. A number of particular types have been examined in previous studies of elastic critical buckling and post-buckling of shells, the two most significant of which are defined by Eqs. (1) and (2). Other geometries have been described by Marguerre [3]. 
The curve defined by Eq. (1) is convenient because it can be used to generate a family of ovals of varying aspect ratio, but constant circumferential length, thereby providing a rational basis for comparisons.

$$
r=\frac{r_{0}}{1+\xi \cos \left(\frac{4 \pi S}{L_{0}}\right)}
$$

where $r$ is the local radius of curvature, $r_{0}$ is the radius of a circle of circumference equal to that of the oval, $\xi$ is a measure of eccentricity (ovality) ranging between zero and unity (to ensure convexity of the shell), $\mathrm{s}$ is the circumferential coordinate (see Figure 1) and $\mathrm{L}_{0}$ is the circumferential length of the oval measured along the centreline of the wall thickness.

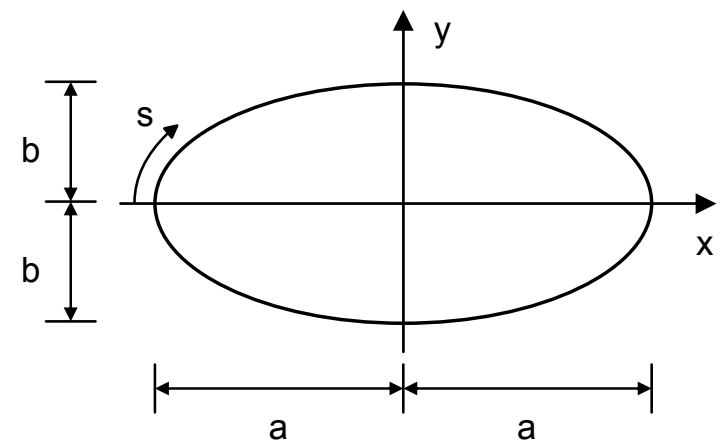

Figure 1. Geometry of oval sections

Eq. (2) defines the geometry of an ellipse. The nature of the expression enables direct and straightforward determination of many of the geometric properties, whilst other properties may be calculated by integration. Standardised section properties may be obtained from prEN 10210-2 (2003) [4]. The oval hollow sections described in the current study are of elliptical geometry.

$$
\left(\frac{x}{a}\right)^{2}+\left(\frac{y}{b}\right)^{2}=1
$$

where $\mathrm{x}$ and $\mathrm{y}$ are the Cartesian coordinates and $\mathrm{a}$ and $\mathrm{b}$ are the major and minor radii, respectively (see Figure 1).

Currently, few test results on oval hollow sections exist and there is a limited understanding of their properties and structural performance at both a cross-sectional and member level. Early test results on oval sections of non-metallic materials and of very slender proportions have been conducted by the aeronautical sector, including those by Hutchinson [5], Feinstein et al. [6] and Tennyson et al. [7]. Tentative design rules for structural oval hollow sections, based on assumed analogies with circular hollow sections have been proposed by the Steel Construction Institute and Corus Tubes $[8,9]$, which although rationally based, have no theoretical, numerical or experimental verification.

The elastic critical buckling and post-buckling behaviour of oval shells first received attention from the aeronautical industry in the 1950s and 1960s, with the principal investigations conducted in the USA. Following examination of the behaviour of shells of varying curvature [3], analyses to predict the elastic critical buckling and post-buckling response of oval hollow sections under axial loading were conducted $[10,11]$. It was proposed that the elastic critical buckling stress for an oval cross-section subjected to pure compression could be approximated by Eq. (3), derived simply by substituting the maximum radius of curvature of an oval section $r_{\max }$ into the classical buckling expression for a circular cylinder [12]. This assumes that buckling would initiate at the point of maximum radius of curvature and ignores the restraining effect of the surrounding material of lower radius of curvature; Eq. (3) is therefore a lower bound solution. 


$$
\sigma_{\mathrm{cr}}=\frac{E t}{r_{\max } \sqrt{3\left(1-v^{2}\right)}}
$$

where $\mathrm{E}$ is the material Young's modulus, $\mathrm{t}$ is the thickness of the cross-section, $v$ is Poisson's ratio and $r_{\max }$ is the maximum radius of curvature of the oval.

For an elliptical section, the maximum radius of curvature occurs at the ends of the minor axis, and may be shown to be equal to $\mathrm{a}^{2} / \mathrm{b}$, where $\mathrm{a}$ and $\mathrm{b}$ are the major and minor axis radii (Figure 1 ). Thus, the elastic critical buckling stress for an elliptical cylinder may be approximated by Eq. (4).

$$
\sigma_{\mathrm{cr}}=\frac{E t}{\left(\frac{a^{2}}{b}\right) \sqrt{3\left(1-v^{2}\right)}}
$$

Note that for the case where $a=b$, Eq. (4) reverts exactly to the elastic critical buckling stress of a circular cylinder, whilst for high $\mathrm{a} / \mathrm{b}$ ratios the critical buckling stress approaches that predicted by the classical buckling expression for a flat plate.

The post-buckling response of a axially compressed circular cylindrical shell differs markedly from that of a flat plate, as indicated schematically by Figure 2. Whereas a flat plate exhibits a stable post-buckling response, the initial post-buckling response of an axially compressed circular cylindrical shell is highly unstable, resulting in high imperfection sensitivity and observed failure loads significantly below those predicted by linear theory. The behaviour of an oval section may be assumed to be intermediate between these two bounds, but the transition point $(\mathrm{a} / \mathrm{b}$ ratio) between a stable and an unstable post-buckling response and the associated consequences in terms of ultimate load carrying capacity, has been the subject of some debate $[5,11,13]$. Discrepancies related to whether consideration was being given to the initial post-buckling region or the far post-buckling region, and it has since been demonstrated by experimentation that ultimate loads well in excess of critical buckling loads can be achieved for oval sections of moderate $(\xi=0.5, \mathrm{a} / \mathrm{b}=1.40)$ to extreme $(\xi=1.0, \mathrm{a} / \mathrm{b}=2.07)$ proportions [6].

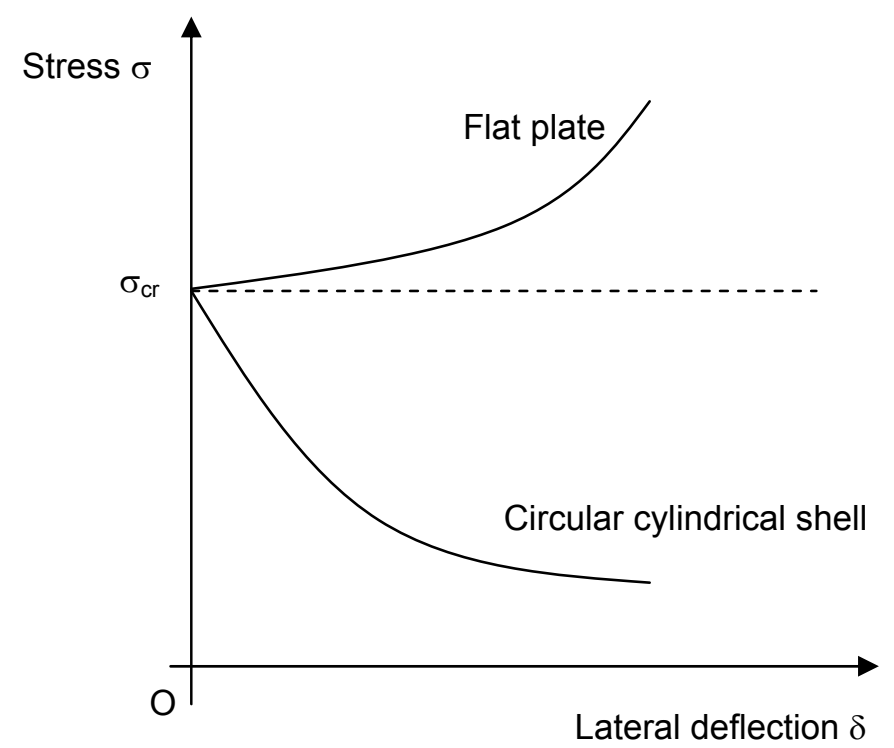

Figure 2. Schematic post-buckling response of an axially compressed circular cylindrical shell and a flat plate

Analysis of the buckling and post-buckling response of oval cylinders in bending and under combined axial compression and bending has also been carried out. For bending about the minor axis, as for pure axial compression, buckling may be assumed to initiate at the point of maximum 
radius of curvature, which now also corresponds to the point of maximum compressive stress. For bending about the major axis, buckling, in general, initiates neither at the point of maximum radius of curvature (since this lies on the neutral axis) nor at the point of maximum compressive stress (since the radius of curvature is a minimum at this location). Studies of the point at which buckling initiates in an oval section subjected to combined axial compression and bending (about the major and minor axes) and subsequent examination of the buckling and post-buckling response have been performed and reported [14-16]. The influence of plasticity on the buckling of oval cylinders under axial compression [17] and under bending [18] has also been investigated.

\section{LABORATORY TESTING}

\section{$2.1 \quad$ Introduction}

The investigations described in the previous section have focussed generally on the critical buckling and post-buckling behaviour of slender, elastic oval cylindrical shells of non-structural dimensions. Although fundamental to the understanding of the behaviour of structural oval hollow sections, particularly those with cross-sections of slender proportions where buckling occurs in the elastic material range, this knowledge clearly needs to be supplemented by additional testing and analysis. Two recent experimental programmes to investigate the structural performance of oval hollow sections have been conducted at Imperial College London and at the University of Southampton; the testing details and results of these studies are described herein.

\section{$2.2 \quad$ Imperial College London tests}

Since OHS have only recently been introduced, selection of specimens was limited largely by product availability. Three section sizes were obtained: OHS $150 \times 75 \times 6.3$, OHS $150 \times 75 \times 8.0$ and OHS 300x150x8.0. For each of the two smaller section sizes, two material tensile coupon tests and two stub column tests (in pure compression) were conducted. For the larger section size (OHS $300 \times 150 \times 8.0$ ), three material tensile coupon tests and three stub column tests (in pure compression) were conducted. All material was Grade S355 and supplied by Corus.

\subsection{Material tensile coupon tests}

Tensile coupon tests were carried out to determine to the basic stress-strain characteristics of the material for each of the tested section sizes. The tensile coupon tests were carried out in accordance with EN 10002-1 (2001) [19].

Parallel coupons were machined longitudinally from the two flattest portions of the cross-sections (i.e. along the centrelines of the ends of the minor axis) using a tipped slot-drill (Figure 3). The nominal dimensions of the tensile coupons were $320 \times 30 \mathrm{~mm}$. Holes were drilled and reamed 20 $\mathrm{mm}$ from each end of the coupons for pins to be inserted to prevent slippage of the coupons in the jaws of the testing machine.

Linear electrical strain gauges were affixed at the midpoint of each side of the tensile coupons. A series of overlapping proportional gauge lengths $\mathrm{L}_{0}$ was marked onto the surface of the coupons; the gauge length of proportional test pieces is related to the original cross-sectional of the test piece $\mathrm{S}_{0}$ such that $\mathrm{L}_{0}=5.65 \sqrt{\mathrm{S}_{0}}$. Pressure, strain, displacement and input voltage were all recorded using the data acquisition equipment DATASCAN and logged using the DALITE computer package. All data were recorded at 4 second intervals. 


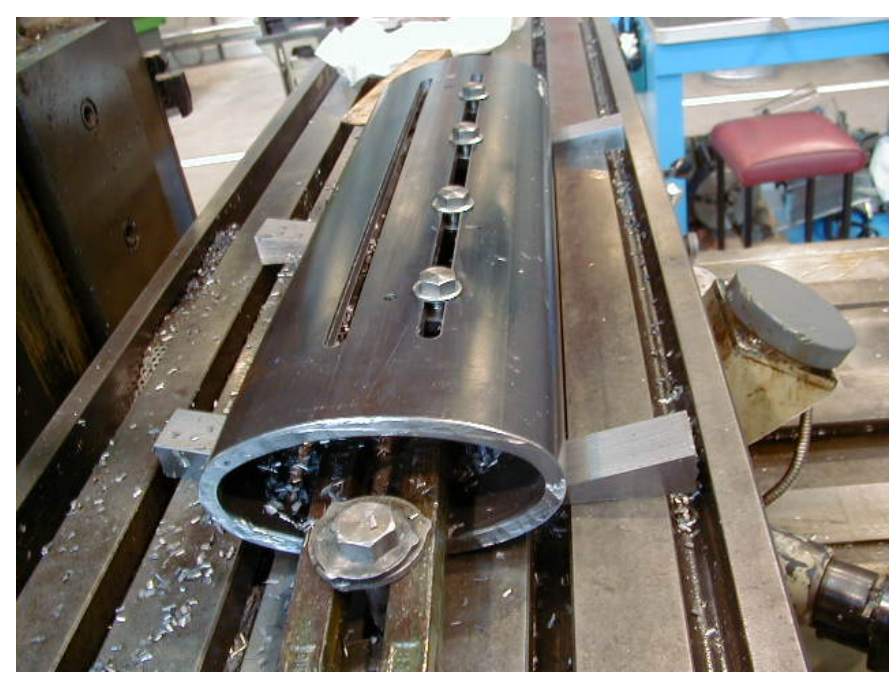

Figure 3. Machining of tensile coupons

The tensile tests were performed using an Amsler $350 \mathrm{kN}$ hydraulic testing machine. Strain rates were within the limits prescribed by EN 10002-1, with fracture occurring, on average, after about 45 minutes.

Mean measured dimensions and key results from the seven coupon tests are reported in Table 1. The stress-strain curves are provided elsewhere [20]. The strain gauges adopted for the OHS $150 \times 75 \times 6.3$ and OHS $150 \times 75 \times 8.0$ material tests were capable of recording strains up to approximately $1 \%$, whereas for the OHS $300 \times 150 \times 8.0$ material tests, high yield strain gauges were utilised enabling strain to be recorded up to approximately $10 \%$. Where material exhibited an upper and lower yield point, it is the lower yield stress that is given in Table 1.

Table 1. Mean measured dimensions and key results from tensile coupon tests

\begin{tabular}{|c|c|c|c|c|c|}
\hline Specimen & $\begin{array}{l}\text { Width } \\
\mathrm{b}_{\mathrm{tc}}(\mathrm{mm})\end{array}$ & $\begin{array}{c}\text { Thickness } \\
\text { t (mm) }\end{array}$ & $\begin{array}{c}\text { Young's } \\
\text { modulus } \\
\text { E }\left(\mathrm{N} / \mathrm{mm}^{2}\right)\end{array}$ & $\begin{array}{l}\text { Yield stress } \\
\sigma_{\mathrm{y}}\left(\mathrm{N} / \mathrm{mm}^{2}\right)\end{array}$ & $\begin{array}{c}\text { Ultimate tensile } \\
\text { stress } \\
\sigma_{\mathrm{u}}\left(\mathrm{N} / \mathrm{mm}^{2}\right)\end{array}$ \\
\hline OHS $150 \times 75 \times 6.3$ & 29.97 & 6.30 & 212100 & 406 & 517 \\
\hline OHS $150 \times 75 \times 6.3$ & 29.91 & 6.35 & 221100 & 415 & 541 \\
\hline OHS $150 \times 75 \times 8.0$ & 29.97 & 8.30 & 209500 & 369 & 502 \\
\hline OHS $150 \times 75 \times 8.0$ & 29.93 & 8.35 & 216700 & 386 & 518 \\
\hline OHS $300 \times 150 \times 8.0$ & 29.90 & 7.63 & 217700 & 415 & 536 \\
\hline OHS 300x150x8.0 & 29.95 & 7.67 & 209600 & 419 & 537 \\
\hline OHS $300 \times 150 \times 8.0$ & 29.93 & 7.79 & 215100 & 408 & 524 \\
\hline
\end{tabular}


A total of seven Oval Hollow Section (OHS) stub columns were tested in pure axial compression to assess load carrying capacity and deformation capacity. Full load-end shortening curves were recorded, including into the post-ultimate range.

The stub column specimens were cut roughly to length using a rotary hacksaw. Their ends were milled flat and square to a tolerance of $\pm 0.02 \mathrm{~mm}$ to achieve accurate seating in the testing machine. Prior to testing, strain visualisation grids were marked onto the surface of the specimens, and measurements of geometry, including initial imperfections were taken.

The nominal lengths of the stub columns were chosen such that they were sufficiently short not to fail by overall buckling, yet still long enough to contain a representative residual stress pattern. A trial stub column test where the length of the specimen was 3 times the larger cross-sectional dimension displayed evidence of overall buckling effects. Subsequent stub column lengths were therefore taken as two times the larger cross-sectional dimension.

Testing of the four OHS 150x75 was carried out in a self-contained $300 \mathrm{~T}$ Amsler hydraulic testing machine (Figure 4a), whilst the three larger OHS 300x150 were tested in a purpose-built test rig (Figure 4b). Both set-ups were load-controlled through an Amsler control cabinet. The end platens of both testing arrangements were fixed flat and parallel.

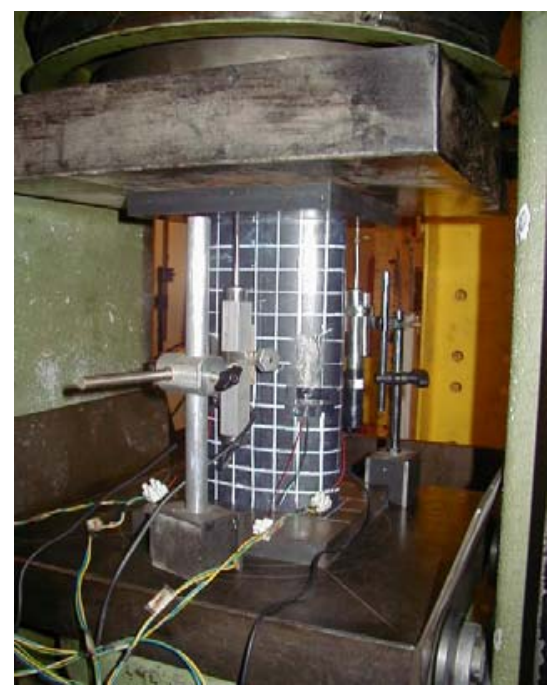

(a) OHS $150 \times 75$

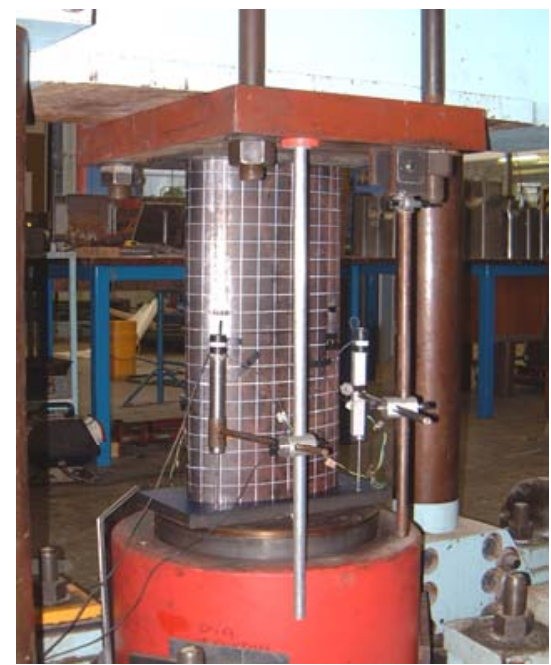

(b) OHS $300 \times 150$

Figure 4. Testing arrangements for stub columns

Three linear variable displacement transducers (LVDTs) were used to determine the end shortening of the stub columns, between the end platens of the testing machine. Figure 5 shows a schematic view of their layout. Four linear electrical resistance strain gauges were affixed to each specimen at mid-height, and at a distance of four times the material thickness from the major axis. The strain gauges were initially used for alignment purposes. Load, strain, displacement, and input voltage were all recorded using the data acquisition equipment DATASCAN and logged using the DALITE computer package. All data were recorded at 2 second intervals.

Alignment of the specimens was necessary to ensure that the compressive load was introduced concentrically. This was carried out by applying a small alignment load to the specimens, approximately $10 \%$ of the predicted failure load $\mathrm{F}_{\mathrm{u} \text {,pred }}$ and observing the variation in strain around the cross-section. In all cases the variation between strains at any point from the average strain was 
less than 5\%. Linearity of the stress-strain plot was used to confirm that the alignment load was below the proportional limit.

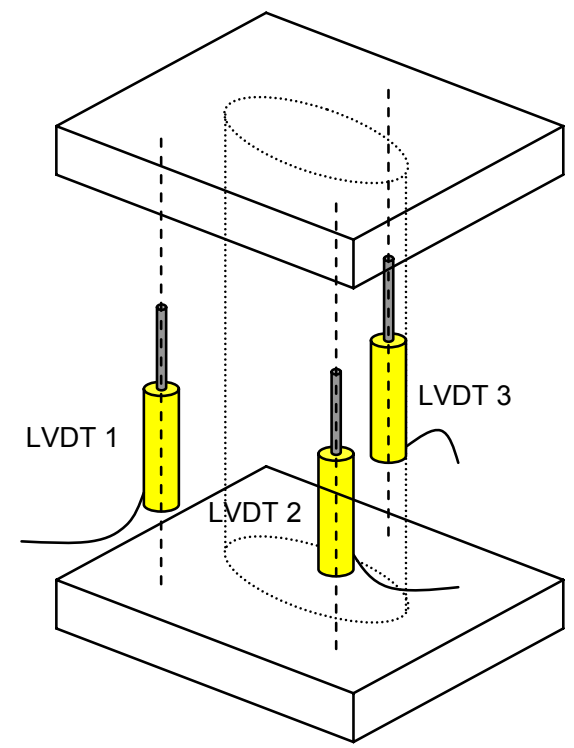

Figure 5. Location of displacement transducers

Loading rates during testing were set such that ultimate load would be reached after 30-45 minutes, and the test would be completed following an appropriate amount of unloading after 60-80 minutes.

Measurements of major and minor axis diameters, material thickness and stub column length were taken at four different points. The mean measured dimensions for the stub column specimens are presented in Table 2. The cross-sectional area $A_{c}$ of the test specimens was calculated from the measured values of major and minor axis outer diameters and thickness, through Eq. (5).

$$
\text { Cross-sectional area } \mathrm{A}_{\mathrm{c}} \quad=\quad \pi \mathrm{AB}-\pi(\mathrm{A}-2 \mathrm{t})(\mathrm{B}-2 \mathrm{t})
$$

Table 2. Mean measured dimensions of stub column specimens

\begin{tabular}{|c|c|c|c|c|c|}
\hline Specimen & $\begin{array}{c}\text { Major axis } \\
\text { outer diameter } \\
2 \mathrm{a}(\mathrm{mm}) \\
\end{array}$ & $\begin{array}{c}\text { Minor axis } \\
\text { outer diameter } \\
2 \mathrm{~b}(\mathrm{~mm})\end{array}$ & $\begin{array}{l}\text { Thickness } \\
\mathrm{t}(\mathrm{mm}) \\
\end{array}$ & $\begin{array}{c}\text { Area } \\
\mathrm{A}_{\mathrm{c}}\left(\mathrm{mm}^{2}\right) \\
\end{array}$ & $\begin{array}{l}\text { Length } \\
\mathrm{L}(\mathrm{mm}) \\
\end{array}$ \\
\hline OHS $150 \times 75 \times 6.3-\mathrm{SC} 1$ & 149.83 & 74.87 & 6.52 & 2168 & 451.3 \\
\hline OHS $150 \times 75 \times 6.3-\mathrm{SC} 2$ & 150.24 & 75.16 & 6.34 & 2118 & 298.5 \\
\hline OHS $150 \times 75 \times 8.0-\mathrm{SC} 1$ & 150.11 & 75.10 & 8.66 & 2828 & 302.6 \\
\hline OHS $150 \times 75 \times 8.0-\mathrm{SC} 2$ & 149.17 & 75.07 & 8.51 & 2770 & 297.2 \\
\hline OHS $300 \times 150 \times 8.0-\mathrm{SC} 1$ & 299.67 & 149.99 & 7.95 & 5417 & 598.7 \\
\hline OHS $300 \times 150 \times 8.0-\mathrm{SC} 2$ & 300.04 & 149.79 & 7.97 & 5432 & 599.4 \\
\hline OHS $300 \times 150 \times 8.0-\mathrm{SC} 3$ & 301.64 & 148.90 & 7.80 & 5329 & 600.1 \\
\hline
\end{tabular}

Measurements of local initial geometric imperfections are important in aiding the explanation of structural response and in the development of numerical models. Schafer and Peköz [21] conducted a detailed assessment of initial geometric imperfections on cold-formed channel sections. In their experimental set-up, the specimens were mounted on the table of a milling machine, and a displacement transducer, fitted in the head of the milling machine, was employed to trace the local geometric imperfections. A similar arrangement was adopted by Gardner and Nethercot [22] and in 
the present study (Figure 6), whereby, a mechanical dial gauge indicator was fitted into the head of the milling machine, and the specimens were clamped to the bed. An automatic feed was used to pass the specimen under the dial gauge indicator, along its length. Readings were taken at regular intervals along the centreline of the minor axes of the specimens (Figure 7).

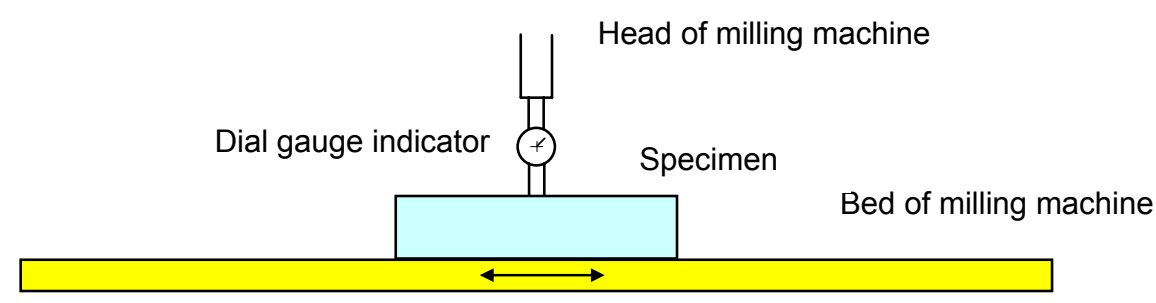

Figure 6. Initial imperfection measurement set-up

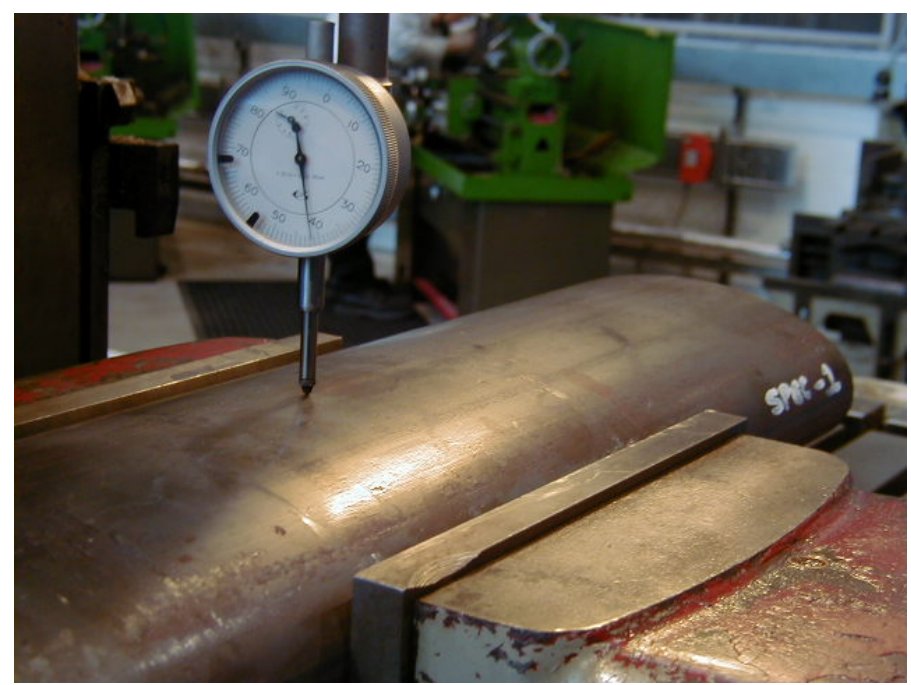

Figure 7. Measurement of initial geometric imperfections

Table 3 presents the maximum initial geometric imperfection magnitudes that were measured along the centrelines of the minor axes of each of the section sizes. The datum for the imperfection measurements is a straight line connecting the ends of each stub column face.

Table 3. Maximum magnitudes of initial geometric imperfections for tested section sizes

\begin{tabular}{l|c}
\hline Specimen & Mean measured maximum imperfection $(\mathrm{mm})$ \\
\hline OHS $150 \times 75 \times 6.3$ & 0.061 \\
\hline OHS $150 \times 75 \times 8.0$ & 0.562 \\
\hline OHS $300 \times 150 \times 8.0$ & 0.633 \\
\hline
\end{tabular}

Compression tests on stub columns reveal the average compressive response of the cross-sections. Ultimate failure is due to local buckling of the cross-section. For cross-sections comprising slender elements local buckling may occur in the elastic material range. For more stocky cross-sections, local buckling will occur following significant inelastic deformation.

Measured end shortening readings from the LVDTs were modified on the basis of the strain gauge readings to account for the elastic deformation of the end platens (that are present in the LVDT 
measurements). Thus true end shortening values were derived, and are utilised in the remainder of this study.

Load-end shortening curves from the stub column tests are shown in Figures 8 to 10. Note that the

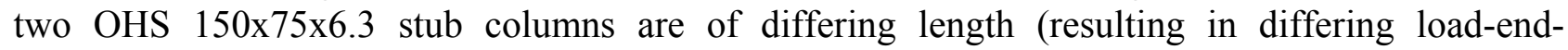
shortening behaviour, as shown in Figure 8). The full load-end shortening curve was not recorded for OHS 300x150x8.0 - SC3.

All stub columns exhibited a similar failure mode whereby the two wider faces of the cross-sections buckled locally. All sections displayed a single half wave across the width of the section, indicating characteristics more closely associated with plate behaviour than shell behaviour.

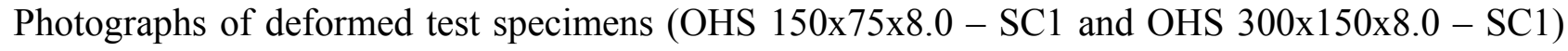
are shown in Figure 11.

A summary of the results from the stub column tests is presented in Table 4. For each test, the ultimate load and the end shortening at ultimate load have been tabulated.

Table 4. Summary of results from stub column tests

\begin{tabular}{|c|c|c|}
\hline Specimen identification & $\begin{array}{l}\text { Ultimate load } \\
\qquad F_{\mathrm{u}}(\mathrm{kN})\end{array}$ & $\begin{array}{l}\text { End shortening at } \\
\qquad F_{\mathrm{u}}(\mathrm{mm})\end{array}$ \\
\hline OHS $150 \times 75 \times 6.3-\mathrm{SC} 1$ & 931 & 13.7 \\
\hline OHS $150 \times 75 \times 6.3-\mathrm{SC} 2$ & 952 & 10.5 \\
\hline OHS $150 \times 75 \times 8.0-\mathrm{SC} 1$ & 1367 & 18.1 \\
\hline OHS $150 \times 75 \times 8.0-\mathrm{SC} 2$ & 1435 & 18.8 \\
\hline OHS $300 \times 150 \times 8.0-\mathrm{SC} 1$ & 2777 & 1.6 \\
\hline OHS 300x150x8.0 - SC2 & 2792 & 1.7 \\
\hline OHS $300 \times 150 \times 8.0-\mathrm{SC} 3$ & 2574 & - \\
\hline
\end{tabular}

\section{$2.5 \quad$ University of Southampton tests}

An experimental study into the minor axis bending behaviour of structural OHS was conducted at the University of Southampton [23]. A four-point bending arrangement was employed for all tests. Three different section sizes were considered, OHS $150 \times 75 \times 5.0$, OHS $150 \times 75 \times 6.3$ and OHS $150 \times 75 \times 8.0$; each test was repeated three times, resulting in the total of nine tests. A tensile coupon test was conducted on material from each of the nine test specimens. All material was Grade S355 and supplied by Corus.

\subsection{Material tensile coupon tests}

Tensile coupon tests were conducted on material cut from each of the nine bending test specimens. The nominal dimensions of the coupons were $200 \mathrm{~mm}$ x $20 \mathrm{~mm}$. The tests were displacement controlled and utilised Instron testing machinery. A summary of the results is provided in Table 5, though other than geometric measurements, only yield stress was reported. 


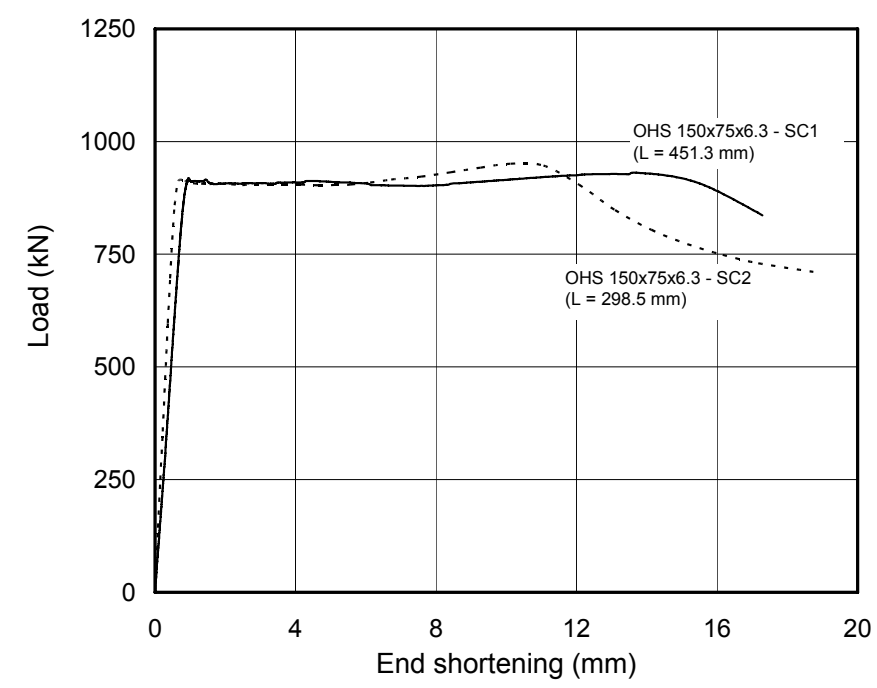

Figure 8. Load-end shortening curves for OHS 150x75x6.3 stub columns

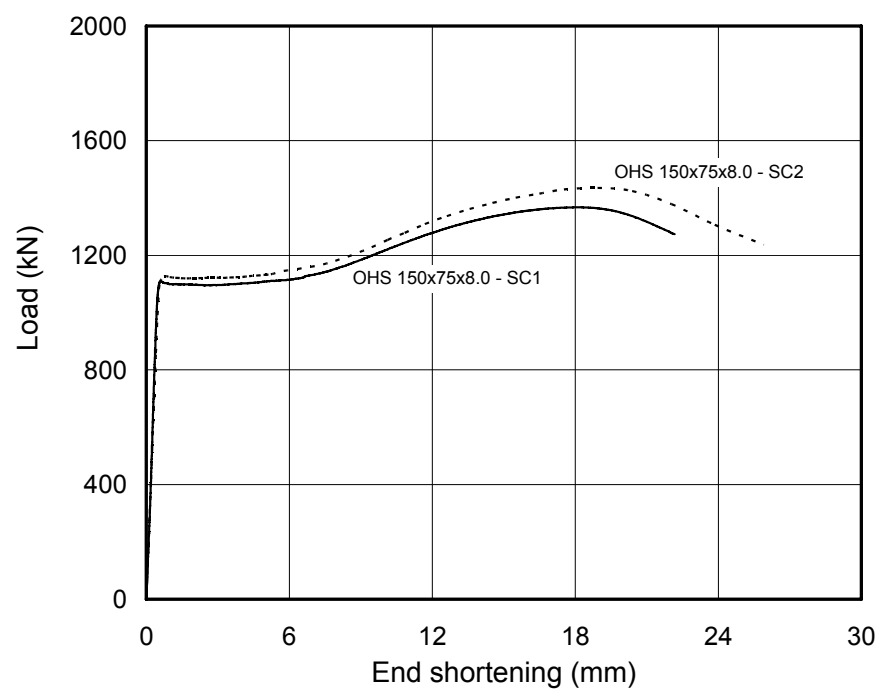

Figure 9. Load-end shortening curves for OHS $150 \times 75 \times 8.0$ stub columns

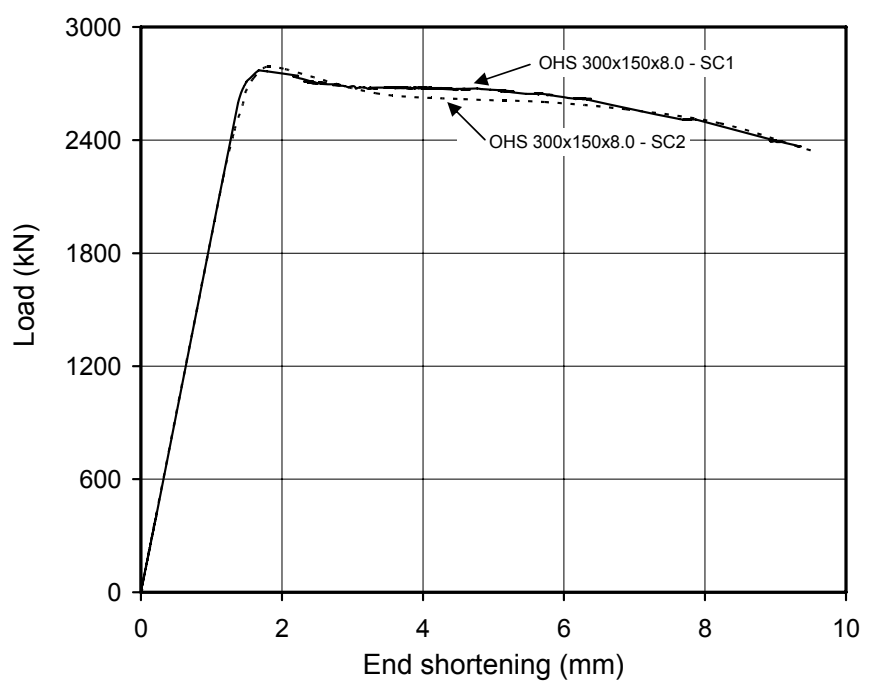

Figure 10. Load-end shortening curves for OHS 300x150x8.0 stub columns 


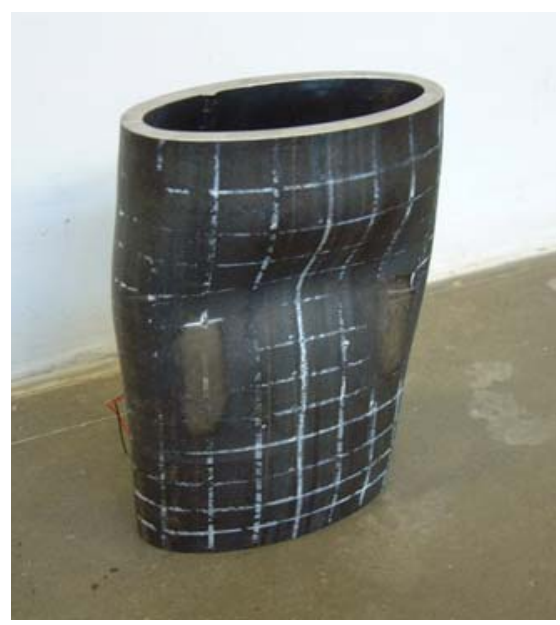

(a) OHS $150 \times 75 \times 8.0-$

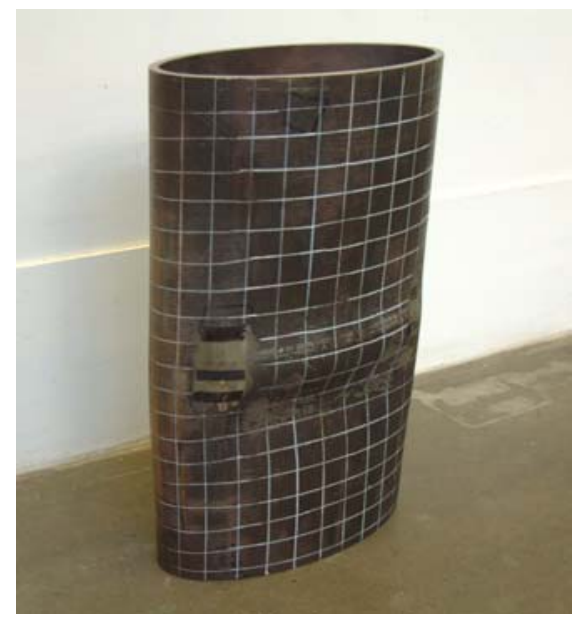

(b) OHS $300 \times 150 \times 8.0-$

Figure 11. Deformed stub column test specimens

Table 5. Minimum measured dimensions and yield stress from tensile coupon tests

\begin{tabular}{l|c|c|c}
\hline Specimen & $\begin{array}{c}\text { Width } \\
\mathrm{b}(\mathrm{mm})\end{array}$ & $\begin{array}{c}\text { Thickness } \\
\mathrm{t}(\mathrm{mm})\end{array}$ & $\begin{array}{c}\text { Yield stress } \\
\sigma_{\mathrm{y}}\left(\mathrm{N} / \mathrm{mm}^{2}\right)\end{array}$ \\
\hline OHS $150 \times 75 \times 5.0-\mathrm{C} 1$ & 19.93 & 5.21 & 367 \\
\hline OHS $150 \times 75 \times 5.0-\mathrm{C} 2$ & 20.00 & 5.11 & 363 \\
\hline OHS $150 \times 75 \times 5.0-\mathrm{C} 3$ & 20.09 & 5.11 & 360 \\
\hline OHS $150 \times 75 \times 6.3-\mathrm{C} 1$ & 19.97 & 6.40 & 380 \\
\hline OHS $150 \times 75 \times 6.3-\mathrm{C} 2$ & 19.96 & 6.44 & 387 \\
\hline OHS $150 \times 75 \times 6.3-\mathrm{C} 3$ & 19.96 & 6.38 & 386 \\
\hline OHS $150 \times 75 \times 8.0-\mathrm{C} 1$ & 19.92 & 8.29 & 366 \\
\hline OHS $150 \times 75 \times 8.0-\mathrm{C} 2$ & 19.91 & 8.32 & 362 \\
\hline OHS $150 \times 75 \times 8.0-\mathrm{C} 3$ & 19.96 & 8.60 & 372 \\
\hline
\end{tabular}

Note that the number of the coupon tests $(\mathrm{C} 1, \mathrm{C} 2$ and $\mathrm{C} 3)$ relates directly to material cut from the bending test specimens (B1, B2 and B3, respectively).

\subsection{In-plane bending tests}

The in-plane minor axis bending tests were conducted in a symmetrical four-point bending arrangement as illustrated in Figure 12. The nominal dimensions for $\mathrm{L}_{1}, \mathrm{~L}_{2}$ and $\mathrm{L}_{3}$ were $1100 \mathrm{~mm}$, $800 \mathrm{~mm}$ and $1100 \mathrm{~mm}$ respectively, with the measured dimensions given in Table 6. Mean measured cross-sectional dimensions of the test specimens are provided in Table 7.

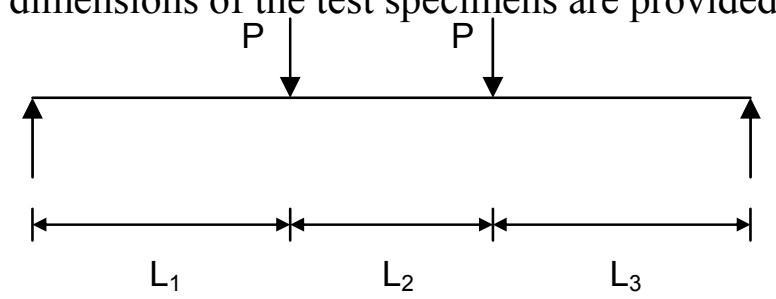

Figure 12. Four-point bending loading arrangement 
Table 6. Measured dimensions for four-point bending arrangements

\begin{tabular}{l|c|c|c}
\hline Specimen & $\mathrm{L}_{1}(\mathrm{~mm})$ & $\mathrm{L}_{2}(\mathrm{~mm})$ & $\mathrm{L}_{3}(\mathrm{~mm})$ \\
\hline OHS $150 \times 75 \times 5.0-\mathrm{B} 1$ & 1089 & 799 & 1088 \\
\hline OHS $150 \times 75 \times 5.0-\mathrm{B} 2$ & 1089 & 800 & 1091 \\
\hline OHS $150 \times 75 \times 5.0-\mathrm{B} 3$ & 1090 & 799 & 1089 \\
\hline OHS $150 \times 75 \times 6.3-\mathrm{B} 1$ & 1088 & 798 & 1090 \\
\hline OHS $150 \times 75 \times 6.3-\mathrm{B} 2$ & 1091 & 800 & 1090 \\
\hline OHS $150 \times 75 \times 6.3-\mathrm{B} 3$ & 1090 & 800 & 1089 \\
\hline OHS $150 \times 75 \times 8.0-\mathrm{B} 1$ & 1089 & 799 & 1093 \\
\hline OHS $150 \times 75 \times 8.0-\mathrm{B} 2$ & 1088 & 799 & 1089 \\
\hline OHS $150 \times 75 \times 8.0-\mathrm{B} 3$ & 1090 & 800 & \\
\hline
\end{tabular}

Table 7. Mean measured cross-sectional dimensions for bending specimens

\begin{tabular}{|c|c|c|c|c|}
\hline Specimen & $\begin{array}{c}\text { Major axis } \\
\text { outer diameter } \\
2 \mathrm{a}(\mathrm{mm})\end{array}$ & $\begin{array}{c}\text { Minor axis } \\
\text { outer diameter } \\
2 \mathrm{~b}(\mathrm{~mm})\end{array}$ & $\begin{array}{l}\text { Thickness } \\
\mathrm{t}(\mathrm{mm})^{1}\end{array}$ & $\begin{array}{c}\text { Area } \\
\mathrm{A}_{\mathrm{c}}\left(\mathrm{mm}^{2}\right)^{1}\end{array}$ \\
\hline OHS $150 \times 75 \times 5.0-\mathrm{B} 1$ & 150.5 & 73.9 & 5.2 & 1763 \\
\hline OHS $150 \times 75 \times 5.0-\mathrm{B} 2$ & 150.6 & 74.2 & 5.2 & 1758 \\
\hline OHS $150 \times 75 \times 5.0-\mathrm{B} 3$ & 150.4 & 74.6 & 5.2 & 1766 \\
\hline OHS $150 \times 75 \times 6.3-\mathrm{B} 1$ & 150.2 & 72.6 & 6.7 & 2195 \\
\hline OHS $150 \times 75 \times 6.3-\mathrm{B} 2$ & 150.2 & 73.5 & 6.7 & 2217 \\
\hline OHS $150 \times 75 \times 6.3-\mathrm{B} 3$ & 150.4 & 73.6 & 6.7 & 2224 \\
\hline OHS $150 \times 75 \times 8.0-\mathrm{B} 1$ & 148.8 & 73.8 & 8.8 & 2823 \\
\hline OHS $150 \times 75 \times 8.0-\mathrm{B} 2$ & 148.9 & 72.8 & 8.8 & 2828 \\
\hline OHS $150 \times 75 \times 8.0-\mathrm{B} 3$ & 148.8 & 73.0 & 9.0 & 2879 \\
\hline
\end{tabular}

Note 1: Area $A_{c}$ and thickness t were calculated from measured mass and density

The results of the bending tests are summarised in Table 8. For each specimen, the maximum test bending moment $\mathrm{M}_{\mathrm{u}}$ attained and the average vertical deflection at the loading points at maximum load $\delta_{\mathrm{u}}$ are given. Full bending moment-deflection graphs for the nine test specimens are shown in Figures 13 to 15 . 


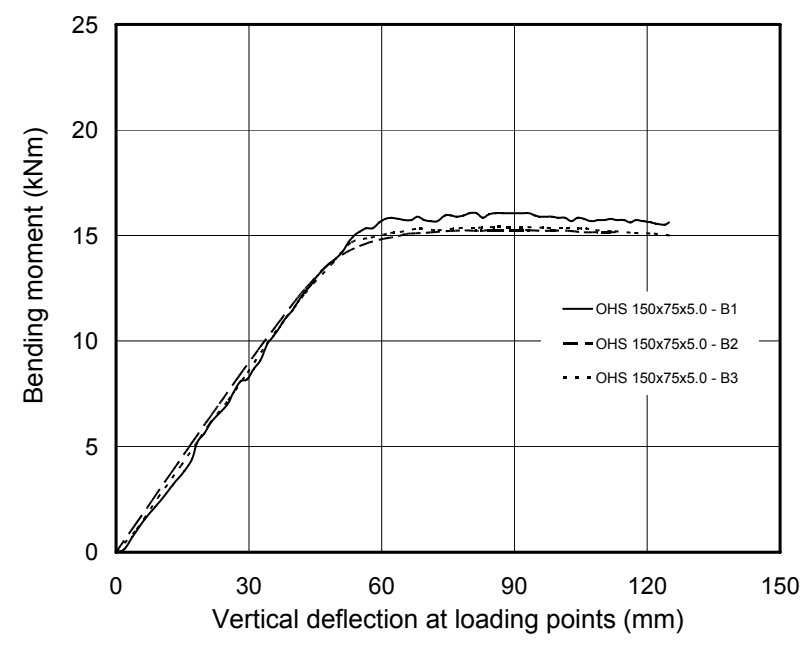

Figure 13. Bending moment-deflection curves for OHS $150 \times 75 \times 5.0$ beams

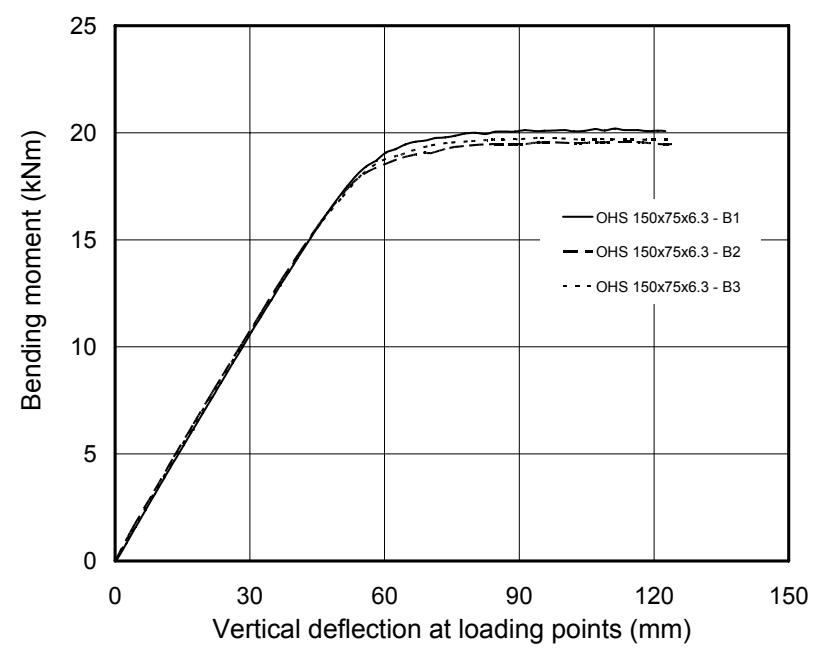

Figure 14. Bending moment-deflection curves for OHS $150 \times 75 \times 6.3$ beams

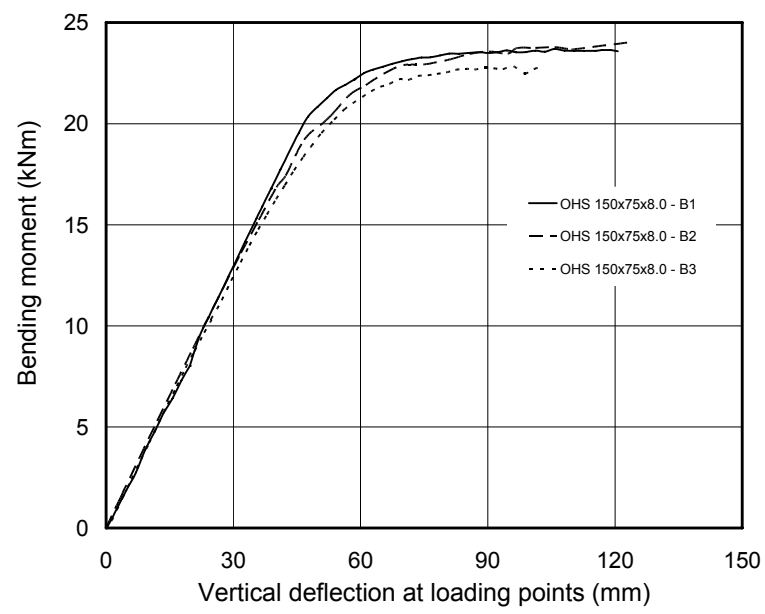

Figure 15. Bending moment-deflection curves for OHS $150 \times 75 \times 8.0$ beams 
Table 8. Summary of results from bending tests

\begin{tabular}{l|c|c}
\hline Specimen & $\begin{array}{c}\text { Ultimate moment } \\
\mathrm{M}_{\mathrm{u}}(\mathrm{kNm})\end{array}$ & $\begin{array}{c}\text { Deflection at ultimate moment } \\
\delta_{\mathrm{u}}(\mathrm{mm})\end{array}$ \\
\hline OHS $150 \times 75 \times 5.0-\mathrm{B} 1$ & 16.1 & 87 \\
\hline OHS $150 \times 75 \times 5.0-\mathrm{B} 2$ & 15.3 & 87 \\
\hline OHS $150 \times 75 \times 5.0-\mathrm{B} 3$ & 15.4 & 111 \\
\hline OHS $150 \times 75 \times 6.3-\mathrm{B} 1$ & 20.2 & 116 \\
\hline OHS $150 \times 75 \times 6.3-\mathrm{B} 2$ & 19.6 & 97 \\
\hline OHS $150 \times 75 \times 6.3-\mathrm{B} 3$ & 19.8 & 106 \\
\hline OHS $150 \times 75 \times 8.0-\mathrm{B} 1$ & 23.7 & 124 \\
\hline OHS $150 \times 75 \times 8.0-\mathrm{B} 2$ & 24.0 & 103 \\
\hline OHS $150 \times 75 \times 8.0-\mathrm{B} 3$ & 22.9 &
\end{tabular}

\section{NUMERICAL MODELLING}

\subsection{Introduction}

A numerical modelling programme was carried out in parallel with the experimental programme at Imperial College London. The initial aim of the numerical work was to replicate the experimental compression and bending behaviour numerically. Subsequent studies were performed to investigate the sensitivity of the models to variation in the key input parameters. All numerical modelling was performed using the non-linear finite element (FE) analysis package, ABAQUS version 6.4 [24].

\subsection{Development of FE models}

\subsubsection{General}

The elements chosen for the FE models were 4-noded, reduced integration shell elements, designated as S4R in the ABAQUS element library, and are suitable for thin or thick shell applications [24]. Convergence studies were conducted to decide upon an appropriate mesh density, with the aim of achieving suitably accurate results whilst minimising computational time. Linear elastic eigenmode simulations were conducted to provide buckling modes to be used as initial imperfections in subsequent non-linear analyses. The modified Riks method [24] was employed to solve the geometrically and materially non-linear stub column and beam models. The modified Riks method is an algorithm that enables effective solutions to be found to unstable problems (e.g. post-ultimate response of compression or flexural members), and adequately traces non-linear unloading paths.

\subsubsection{Material modelling}

ABAQUS requires that material behaviour be specified by means of a multi-linear stress-strain curve, defined in terms of true stress and log plastic strain. The relationships between true stress and engineering stress, $\sigma_{\text {true }}$ and $\sigma_{\text {nom }}$, respectively, and $\log$ plastic strain and engineering strain, $\varepsilon_{\text {ln }}^{p l}$ and $\varepsilon_{\text {nom, }}$, respectively, are given in Eqs. (6) and (7) respectively. Engineering stress and strain are of course the nominal values that are recorded from an uniaxial stress-strain coupon test. 


$$
\begin{aligned}
\sigma_{\text {true }} & =\sigma_{\text {nom }}\left(1+\varepsilon_{\text {nom }}\right) \\
\varepsilon_{\text {in }}^{\mathrm{pl}} & =\ln \left(1+\varepsilon_{\text {nom }}\right)-\frac{\sigma_{\text {true }}}{\mathrm{E}}
\end{aligned}
$$

The measured material properties taken from the tensile coupon tests were adopted in all cases. Where incomplete stress-strain data were available average properties (such as Young's modulus) from the remaining coupon tests were used; this was deemed acceptable since there was little variation in material properties between specimens.

\subsubsection{Residual stresses and initial geometric imperfections}

Residual stresses were not incorporated in the FE models in this study. The reason for this was two-fold. Firstly, no residual stress measurements have been conducted on structural steel oval hollow sections, and secondly, there was no evidence of residual stresses during the preparation of the tensile coupons (that were machined from within the completed oval hollow sections); i.e. the deformation of the coupons as they were released from the surrounding material was very small. However, residual stresses may have been induced as a result of thermal action in the University of Southampton bending tests, where plates were welded to the specimens at the loading and support points. Residual stress measurements would be useful in future studies.

For the stub column models local geometric imperfections of the form of the lowest eigenmode were included in the non-linear analysis. The shape of the three lowest eigenmodes for OHS 150x75.6.3 - SC2 are shown in Figure 16. For the bending models, both local and global geometric imperfections were included in the models. To generate the imperfection modes for the beam models, the bending arrangement was initially replaced by an axial compression arrangement with pin-ends; subsequently, for the non-linear bending analysis, the local imperfection took the form of the lowest local buckling mode and the global imperfection took the form of the lowest global buckling mode.

Due to the limited detail of imperfection measurements, the local imperfection amplitude for the stub columns was considered as a series of fixed fractions of the material thickness $(t / 10, t / 100$ and $\mathrm{t} / 500$ ), whilst the global imperfection amplitude for the beam models was taken as a fixed fraction of the beam length $(\mathrm{L} / 2000)$.
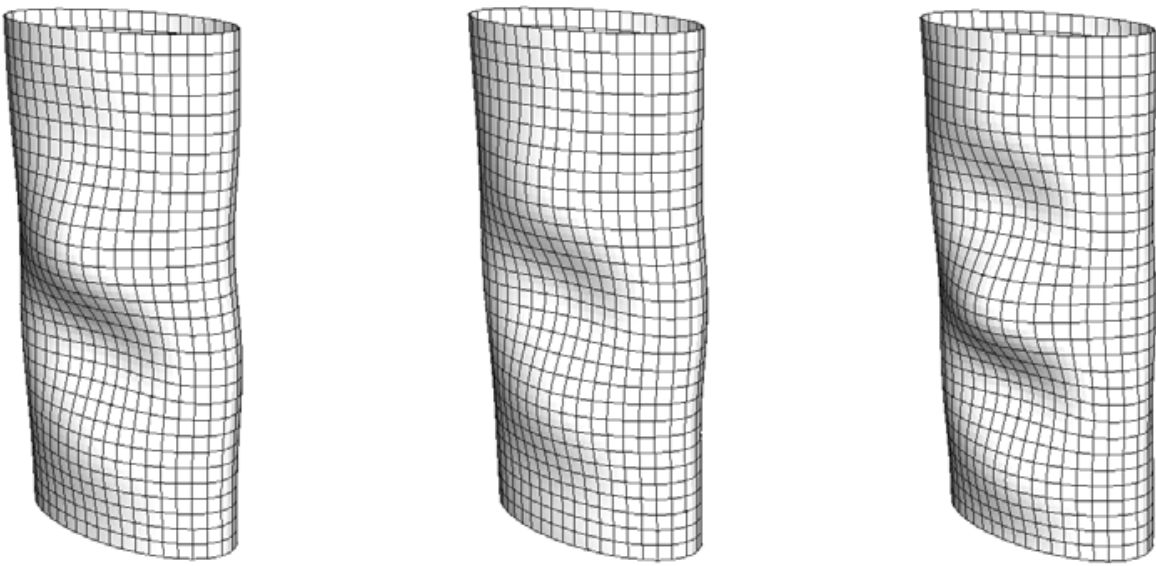

Figure 16. Three lowest eigenmodes for OHS 150x75x6.3 - SC2 


\subsection{Simulation of tests}

\subsubsection{Stub column tests}

The stub column tests were modelled using the measured dimensions of the test specimens, material stress-strain data from the corresponding tensile tests and geometric imperfections of the form of the lowest elastic eigenmode. To assess the sensitivity of the models to variation in imperfections, three different amplitudes were considered $-\mathrm{t} / 10, \mathrm{t} / 100$ and $\mathrm{t} / 500$, where $\mathrm{t}$ is the material thickness. Boundary conditions were applied to model fixed ends. This was achieved by restraining all displacements and rotations at the base of the columns, and all bar vertical displacement at the loaded end of the stub column. Constraint equations were used to ensure that the loaded end of the stub column remained in a horizontal plane.

A comparison of the FE results with the test results for the stub columns is given in Table 9; values of ultimate load $\mathrm{F}_{\mathrm{u}}$ and deformation at ultimate load $\delta_{\mathrm{u}}$ are compared. Table 9 demonstrates that test ultimate load can generally be closely predicted numerically, and is relatively insensitive to imperfection amplitude. In all cases the ultimate load in under-predicted; this is assumed to be largely due to inaccurate material modelling (including use of tensile coupon tests to represent compressive stress-strain properties). However, the deformation at ultimate load is very sensitive to the exact level of imperfection, and this is not reliably predicted using the described models. This is a commonly observed problem and due principally to the sensitivity of numerical models at points of very low stiffness (i.e. near ultimate load, a small increment of load corresponds to a very large increment of deformation). This matter will receive further attention in future studies.

Table 9. Comparison of FE and test results for OHS stub columns

\begin{tabular}{|c|c|c|c|c|c|c|}
\hline \multirow{2}{*}{$\begin{array}{l}\text { Imperfection amplitude } \\
\text { Specimen identification }\end{array}$} & \multicolumn{2}{|c|}{$\mathrm{t} / 500$} & \multicolumn{2}{|c|}{$\mathrm{t} / 100$} & \multicolumn{2}{|c|}{$\mathrm{t} / 10$} \\
\hline & $\begin{array}{l}\mathrm{FE} \mathrm{F}_{\mathrm{u}} / \\
\text { Test } \mathrm{F}_{\mathrm{u}}\end{array}$ & $\begin{array}{l}\text { FE } \sigma_{\mathrm{u}} / \\
\text { Test } \sigma_{\mathrm{u}}\end{array}$ & $\begin{array}{l}\mathrm{FE} \mathrm{F}_{\mathrm{u}} / \\
\text { Test } \mathrm{F}_{\mathrm{u}}\end{array}$ & $\begin{array}{l}\text { FE } \sigma_{\mathrm{u}} / \\
\text { Test } \sigma_{\mathrm{u}}\end{array}$ & 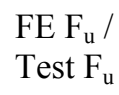 & $\begin{array}{l}\text { FE } \sigma_{\mathrm{u}} / \\
\text { Test } \sigma_{\mathrm{u}}\end{array}$ \\
\hline OHS $150 \times 75 \times 6.3-\mathrm{SC} 1$ & 0.99 & 0.39 & 0.99 & 0.38 & 0.97 & 0.07 \\
\hline OHS $150 \times 75 \times 6.3-\mathrm{SC} 2$ & 0.96 & 0.23 & 0.96 & 0.18 & 0.92 & 0.06 \\
\hline OHS $150 \times 75 \times 8.0-\mathrm{SC} 1$ & 0.83 & 0.83 & 0.83 & 0.82 & 0.79 & 0.04 \\
\hline OHS $150 \times 75 \times 8.0-\mathrm{SC} 2$ & 0.80 & 0.81 & 0.79 & 0.81 & 0.75 & 0.04 \\
\hline OHS $300 \times 150 \times 8.0-\mathrm{SC} 1$ & 0.95 & 0.93 & 0.95 & 0.99 & 0.93 & 0.91 \\
\hline OHS $300 \times 150 \times 8.0-\mathrm{SC} 2$ & 0.95 & 0.97 & 0.95 & 0.97 & 0.92 & 0.91 \\
\hline
\end{tabular}

Figure 17 compares the load-end shortening response of the OHS 300x150x8.0 - SC1 test with the FE models containing the three different imperfection amplitudes. Note that the results of the FE models with imperfection amplitudes of $t / 100$ and $t / 500$ are almost coincident.

The failure modes of the FE models were similar to those observed in the tests. An example of a deformed FE stub column model (OHS 150x75x6.3 - SC1) is shown in Figure 18. 


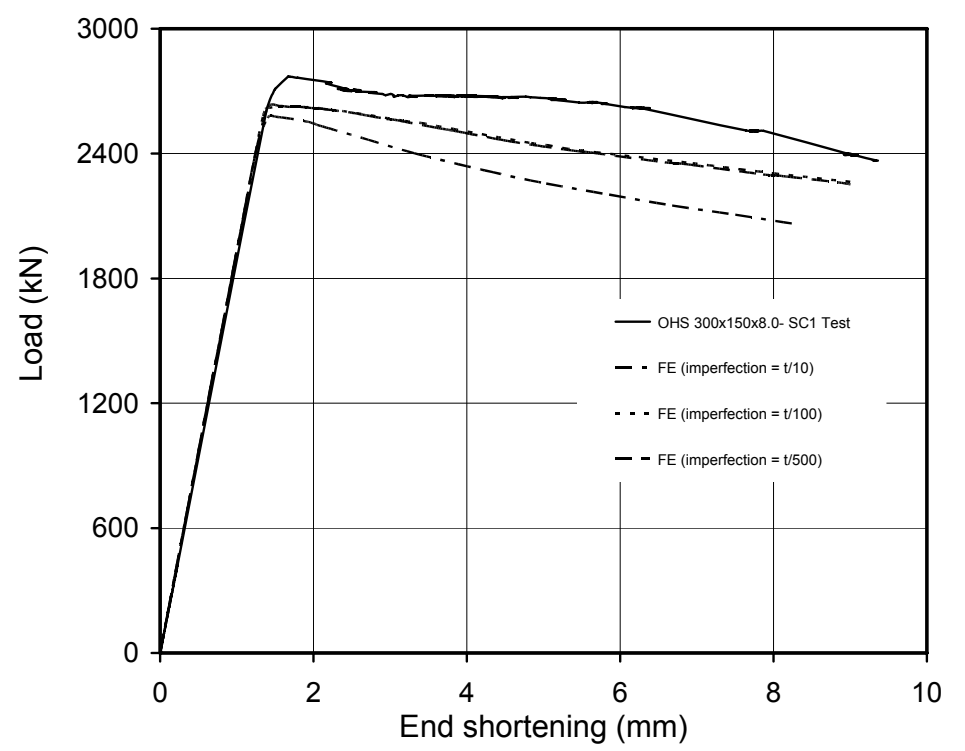

Figure 17. Comparison between test and FE model of OHS 300x150x8.0 - SC1 stub column

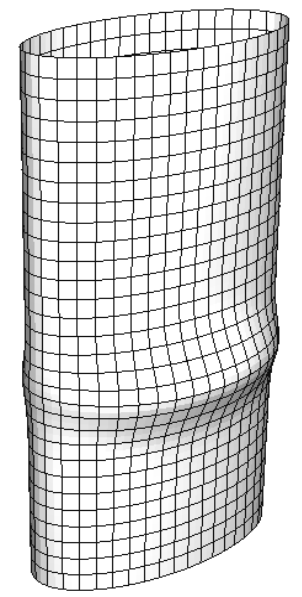

Figure 18. Deformed FE model of OHS $150 \times 75 \times 6.3$ stub column

\subsubsection{Bending tests}

The bending tests conducted at the University of Southampton were modelled using the measured dimensions of the test specimens, material stress-strain data from the corresponding tensile tests and local and global geometric imperfections of the form of the lowest elastic eigenmodes. Since only values of yield strength were reported from the University of Southampton tests, mean values of other material properties such as Young's modulus and ultimate strength were assumed as the mean values from the Imperial College London tests. Initial studies demonstrated that the models were not sensitive to variation in imperfection amplitude; therefore a local imperfection amplitude of $t / 100$ and a global imperfection amplitude of L/2000 were employed throughout the study. A general view of the FE model of the bending set-up is shown in Figure 19.

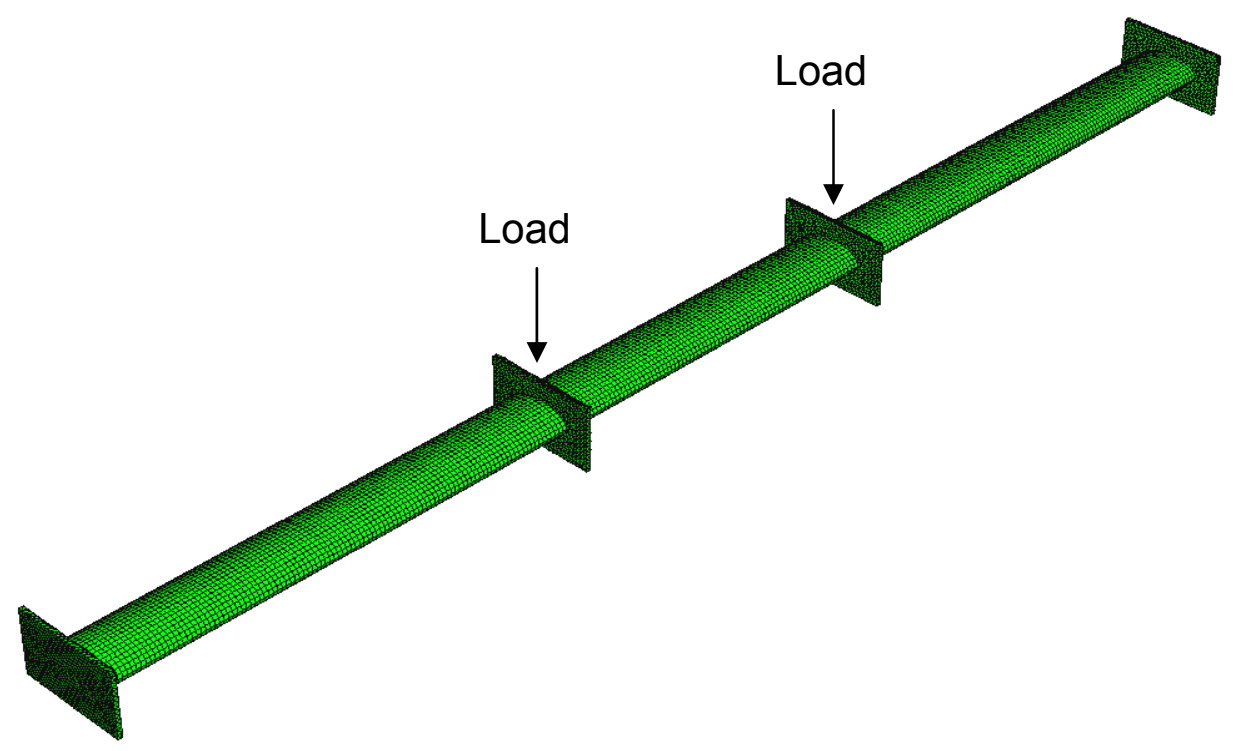

Figure 19. General view of FE model of bending set-up

A comparison of the FE results with the test results for the beams is given in Table 10; values of ultimate moment $\mathrm{M}_{\mathrm{u}}$ and average vertical deflection at the loading points at ultimate moment $\delta_{\mathrm{u}}$ are compared. Graphical comparisons between test and FE results for bending moment versus vertical displacement at the loading points are shown in Figures 20 to 22. 


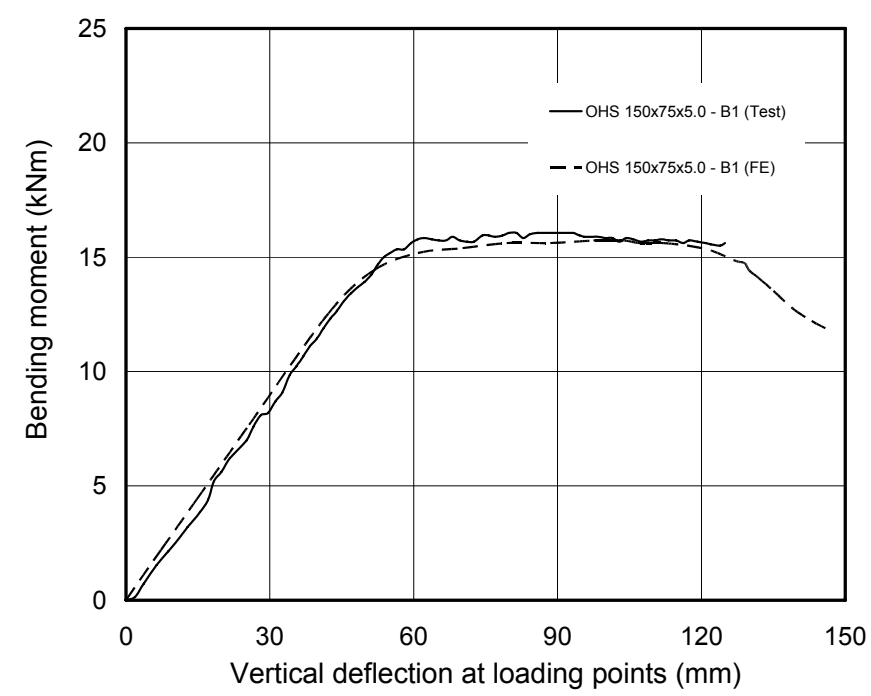

Figure 20. Comparison of bending moment versus deformation for OHS 150x75x5.0 - B1

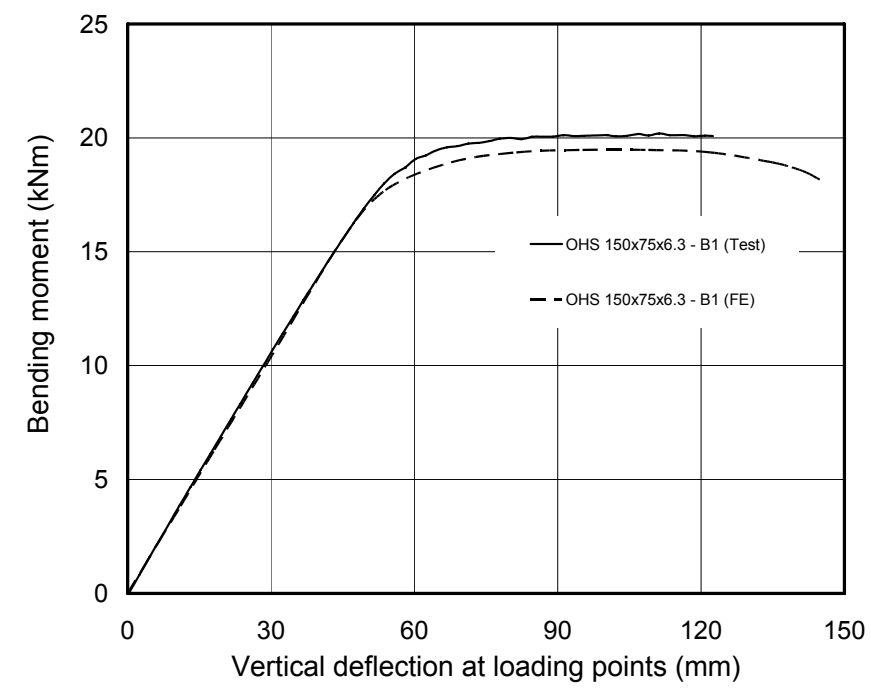

Figure 21. Comparison of bending moment versus deformation for OHS 150x75x6.3 - B1

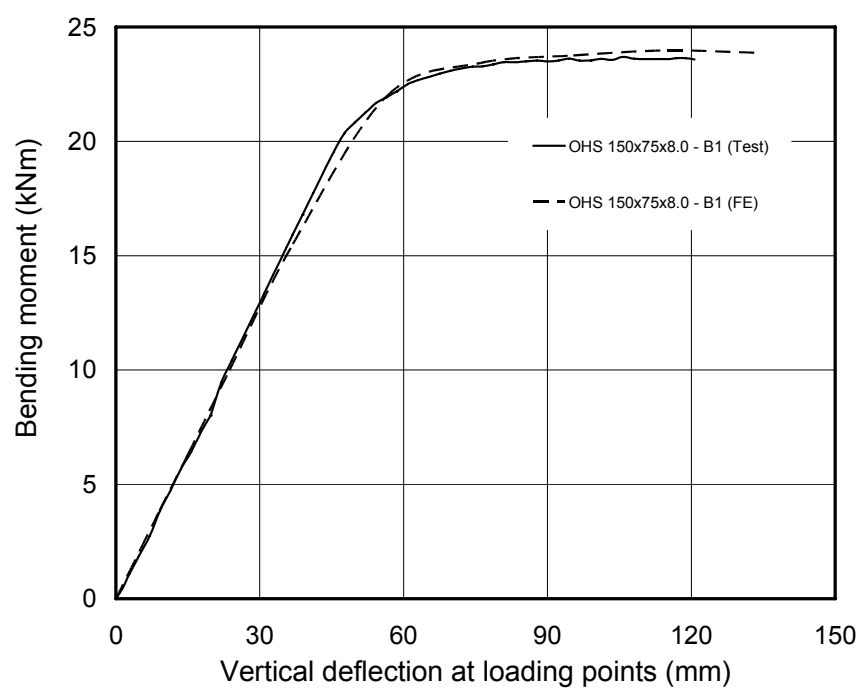

Figure 22. Comparison of bending moment versus deformation for OHS $150 \times 75 \times 8.0-\mathrm{B} 1$ 
Table 10. Comparison of FE and test results for OHS beams

\begin{tabular}{l|c|c|c|c}
\hline Specimen & $\begin{array}{c}\text { FE ultimate } \\
\text { moment } \\
\mathrm{M}_{\mathrm{u}}(\mathrm{kNm})\end{array}$ & $\begin{array}{c}\text { FE deflection at } \\
\text { ultimate moment } \\
\delta_{\mathrm{u}}(\mathrm{mm})\end{array}$ & $\begin{array}{c}\mathrm{FE} \mathrm{M}_{\mathrm{u}} / \\
\mathrm{Test} \mathrm{M}_{\mathrm{u}}\end{array}$ & $\begin{array}{c}\text { FE } \sigma_{\mathrm{u}} / \\
\text { Test } \sigma_{\mathrm{u}}\end{array}$ \\
\hline OHS $150 \times 75 \times 5.0-\mathrm{B} 1$ & 15.7 & 101 & 1.03 & 1.16 \\
\hline OHS $150 \times 75 \times 5.0-\mathrm{B} 2$ & 15.7 & 99 & 1.02 & 1.14 \\
\hline OHS $150 \times 75 \times 5.0-\mathrm{B} 3$ & 15.7 & 99 & 0.97 & 0.92 \\
\hline OHS $150 \times 75 \times 6.3-\mathrm{B} 1$ & 19.5 & 102 & 0.99 & 0.90 \\
\hline OHS $150 \times 75 \times 6.3-\mathrm{B} 2$ & 19.5 & 104 & 0.99 & 1.07 \\
\hline OHS $150 \times 75 \times 6.3-\mathrm{B} 3$ & 19.6 & 104 & 1.01 & 0.98 \\
\hline OHS $150 \times 75 \times 8.0-\mathrm{B} 1$ & 24.0 & 115 & 1.00 & 0.94 \\
\hline OHS $150 \times 75 \times 8.0-\mathrm{B} 2$ & 23.9 & 116 & 1.05 & 1.12 \\
\hline OHS $150 \times 75 \times 8.0-\mathrm{B} 3$ & 24.1 & & & 0.99 \\
\hline
\end{tabular}

The FE failure modes mirrored the test failure modes, with in-plane bending only. The bending was generally symmetrical, though in some cases non-symmetrical deformations were observed beyond the ultimate bending moment (due to slight non-symmetry in the test geometry). A typical FE failure mode is shown in Figure 23.

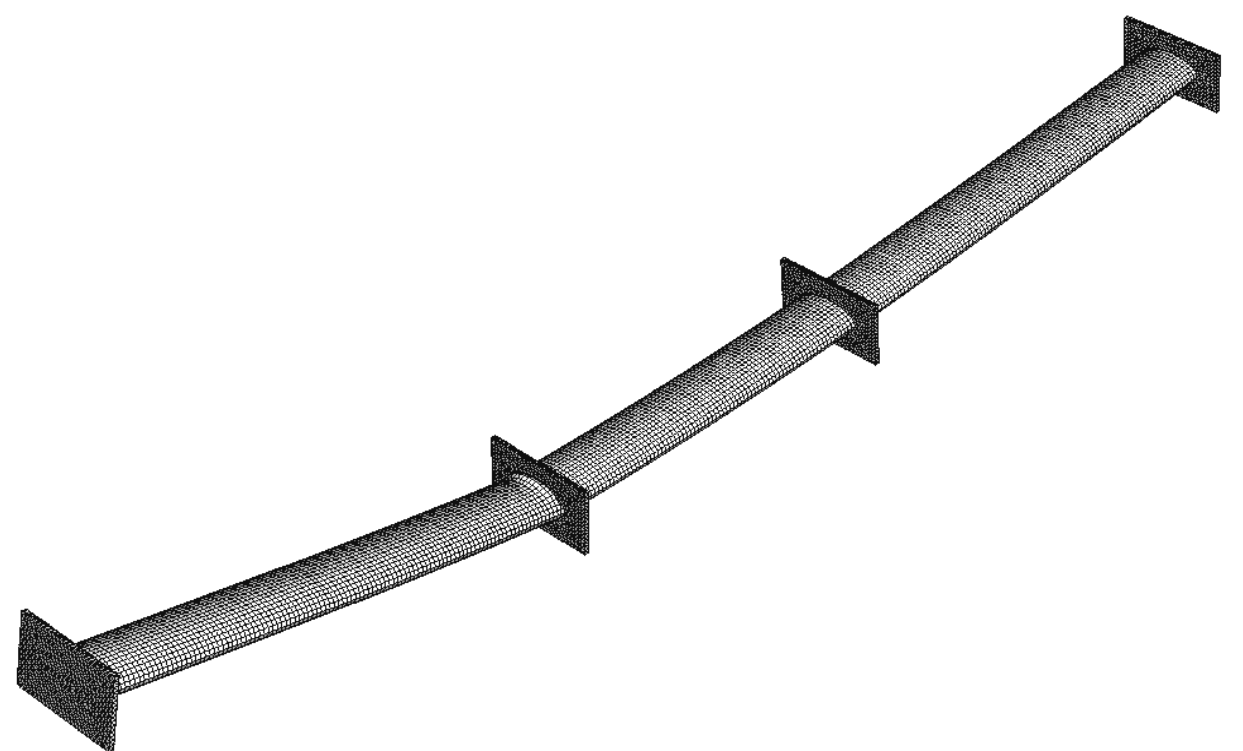

Figure 23. Typical FE failure mode for bending arrangement

\subsection{Parametric studies}

Following the satisfactory agreement between test and FE model behaviour, this section presents parametric studies, intended to analyse trends and generate a greater pool of results.

\subsubsection{Stub columns}

From the comparison between test and FE stub column behaviour, it was shown that ultimate load was adequately predicted, but deformation at ultimate load was not well predicted. A parametric study has been conducted to determine ultimate loads for stub columns of varying slenderness, with 
the results compared against the yield load for each cross-section, to investigate the effects of strain hardening for the stocky sections and elastic local buckling in the slender sections. Variation in slenderness was achieved by altering the thickness of the OHS 150x75. Mean values for material properties were taken from the tensile tests performed at Imperial College London, whilst initial geometric imperfections were taken as the lowest eigenmode with an amplitude of $t / 500$. The results are presented in Table 11.

Table 11. Results of parametric study to investigate stub column behaviour

\begin{tabular}{l|c|c|c}
\hline Section & $\begin{array}{c}\text { FE ultimate load } \\
\mathrm{F}_{\mathrm{u}}(\mathrm{kN})\end{array}$ & $\begin{array}{c}\text { Calculated yield load } \\
\mathrm{F}_{\mathrm{y}}(\mathrm{kN})\end{array}$ & $\mathrm{F}_{\mathrm{u}} / \mathrm{F}_{\mathrm{y}}$ \\
\hline OHS $150 \times 75 \times 3.0$ & 379 & 424 & 0.89 \\
\hline OHS $150 \times 75 \times 4.0$ & 506 & 560 & 0.90 \\
\hline OHS $150 \times 75 \times 5.0$ & 636 & 694 & 0.92 \\
\hline OHS $150 \times 75 \times 6.3^{1}$ & 919 & 875 & 1.05 \\
\hline OHS $150 \times 75 \times 8.0^{1}$ & 1130 & 1058 & 1.07 \\
\hline
\end{tabular}

Note: ${ }^{1}$ Replication of test

The results demonstrate that the two stockier sections (OHS $150 \times 75 \times 6.3$ and OHS $150 \times 75 \times 8.0$ ) are capable of achieving and exceeding their respective yield loads. The more slender OHS $150 \times 75 \times 5.0$, OHS $150 \times 75 \times 4.0$ and OHS $150 \times 75 \times 3.0$ do not reach their yield load due to the effects of local buckling in the elastic material range, which, as expected, can be seen to be more detrimental with increasing slenderness.

\subsubsection{Beams}

From the comparison between tests and FE bending behaviour, it was shown that the ultimate moment, deformation at ultimate moment, and indeed the full bending moment-deformation history was well predicted. Thus a parametric study has been conducted to generate bending momentdeformation histories for a range of cross-section slenderness. As with the stub column models, this was achieved through variation in section thickness. Material properties were taken as the mean values from the tensile tests conducted at the University of Southampton on material cut from the bending specimens. Local and global imperfections were introduced as described previously in this paper.

The results of the parametric study are shown in Figure 24, with the bending moments normalised by the plastic bending resistance of each of the cross-sections.

Figure 24 demonstrates, as expected, that the stockier the cross-section the higher the deformation capacity. The $5.0 \mathrm{~mm}, 6.3 \mathrm{~mm}, 8.0 \mathrm{~mm}$ and $10.0 \mathrm{~mm}$ models all reach the calculated crosssectional plastic bending resistance. The $3.0 \mathrm{~mm}$ and $4.0 \mathrm{~mm}$ models display a lower deformation capacity and do not reach the full plastic bending resistance. The $3.0 \mathrm{~mm}$ model reached $92 \%$ of the plastic bending resistance, whilst the $4.0 \mathrm{~mm}$ model reached $97 \%$. Both of these sections exceeded their elastic bending resistances. 


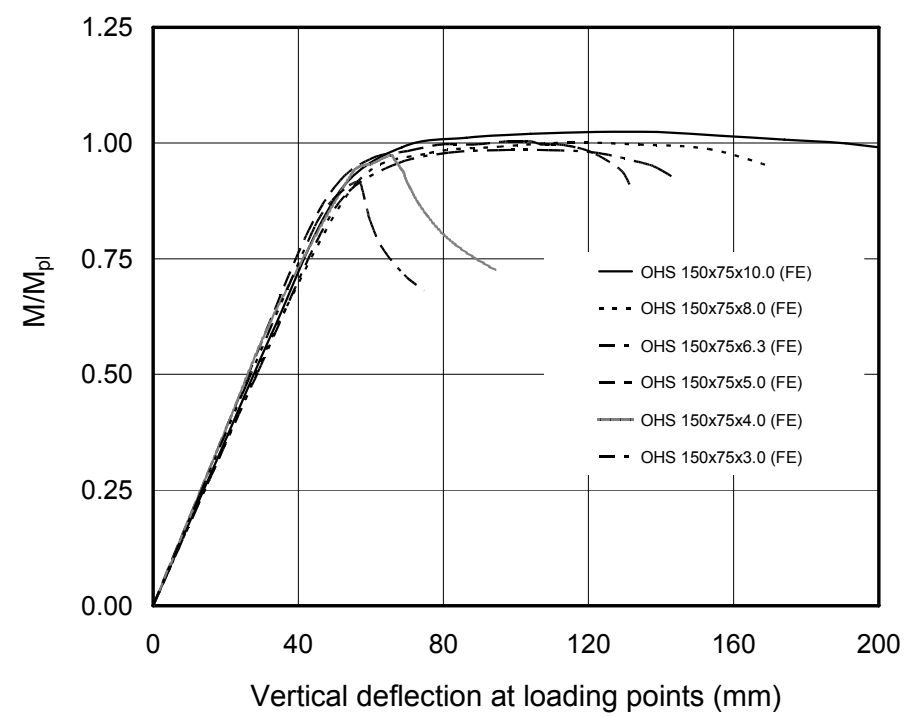

Figure 24. Effect of cross-section slenderness on bending behaviour

\section{COMPARISON WITH PRELIMINARY DESIGN GUIDANCE}

A preliminary method for the section classification of oval hollow sections under the individual loading conditions of axial compression, minor axis bending and major axis bending has been drafted [9]; combined loading was not considered. The classification limits are those contained in prEN 1993-1-1 (2003) [25] for circular hollow sections, but the section slenderness is defined based on an equivalent diameter $D_{e}$, to account for the continuously varying curvature. The classification limits for axial compression and for minor axis bending, with which to compare the diameter-tothickness ratio $(D / t)$ of a circular section (or $D_{e} / t$ for an oval section) are $50 \varepsilon^{2}$ for Class $1,70 \varepsilon^{2}$ for Class 2 and $90 \varepsilon^{2}$ for Class 3 , where $\varepsilon=\left(235 / \sigma_{\mathrm{y}}\right)^{0.5}$ and $\sigma_{\mathrm{y}}$ is the material yield strength. General guidance on the use of EN 1993-1-1 is available [26].

For the configurations considered in the current study (i.e. axial compression and minor axis bending), the equivalent diameter $\mathrm{D}_{\mathrm{e}}$ used to determine the section slenderness is taken as that of an equivalent circle, as given by Eq. (8), where the symbols have been harmonised with those adopted in the remainder of the paper.

$$
D_{e}=2 a \sqrt{\frac{a}{b}}
$$

As shown in Figure 25, the equivalent circle approximately follows the continuously varying curvature of the oval.

The calculated $D_{e} / t$ ratios of the tested specimens and three additional finite element models are given in Table 12, along with their corresponding section classification. EN 1993-1-1 defines four classes of cross-section. Under pure compression, Class 1-3 specimens are capable of reaching their squash (or yield) load $\mathrm{F}_{\mathrm{y}}$, defined as the gross area multiplied by the material yield strength, whilst Class 4 sections fail at a lower load due to local buckling in the elastic material range. In Table 12, the ultimate test (or FE) load $F_{u}$ is normalised by the squash load $F_{y}$, and the relationship between $F_{u} / F_{y}$ and cross-section slenderness $D_{e} / t \varepsilon^{2}$ is plotted in Figure 26. A value of $F_{u} / F_{y}$ greater than unity represents meeting of the Class 1-3 requirements, whilst a value less than unity indicates a Class 4 section where local buckling prevents the yield load being reached. Figure 26 exhibits the 
anticipated trend of reducing values of $\mathrm{F}_{\mathrm{u}} / \mathrm{F}_{\mathrm{y}}$ with increasing slenderness, and indicates that a Class 3 slenderness limit of $90 \varepsilon^{2}$ is reasonable, but requires further investigation.

Table 12. Section classification in compression

\begin{tabular}{|c|c|c|c|c|c|}
\hline Specimen & $\begin{array}{c}\text { Equivalent } \\
\text { diameter } \\
\mathrm{D}_{\mathrm{e}}(\mathrm{mm})\end{array}$ & $\begin{array}{c}\text { Thickness } \\
\mathrm{t}(\mathrm{mm})\end{array}$ & $\mathrm{D}_{\mathrm{e}} / \mathrm{t}$ & $\mathrm{F}_{\mathrm{u}} / \mathrm{F}_{\mathrm{y}}$ & Classification \\
\hline OHS $150 \times 75 \times 6.3-\mathrm{SC} 1$ & 211.96 & 6.52 & 32.5 & 1.06 & Class 2 \\
\hline OHS $150 \times 75 \times 6.3-\mathrm{SC} 2$ & 212.41 & 6.34 & 33.5 & 1.08 & Class 2 \\
\hline OHS $150 \times 75 \times 8.0-\mathrm{SC} 1$ & 212.22 & 8.66 & 24.5 & 1.31 & Class 1 \\
\hline OHS $150 \times 75 \times 8.0-\mathrm{SC} 2$ & 210.28 & 8.51 & 24.7 & 1.34 & Class 1 \\
\hline OHS $300 \times 150 \times 8.0-\mathrm{SC} 1$ & 423.58 & 7.95 & 53.3 & 1.24 & Class 4 \\
\hline OHS $300 \times 150 \times 8.0-\mathrm{SC} 2$ & 424.65 & 7.97 & 53.3 & 1.24 & Class 4 \\
\hline OHS $300 \times 150 \times 8.0-\mathrm{SC} 3$ & 429.32 & 7.80 & 55.0 & 1.18 & Class 4 \\
\hline FE OHS $150 \times 75 \times 5.0$ & 212.13 & 5.00 & 42.4 & 0.92 & Class 3 \\
\hline FE OHS $150 \times 75 \times 4.0$ & 212.13 & 4.00 & 53.0 & 0.90 & Class 4 \\
\hline FE OHS $150 \times 75 \times 3.0$ & 212.13 & 3.00 & 70.7 & 0.89 & Class 4 \\
\hline
\end{tabular}

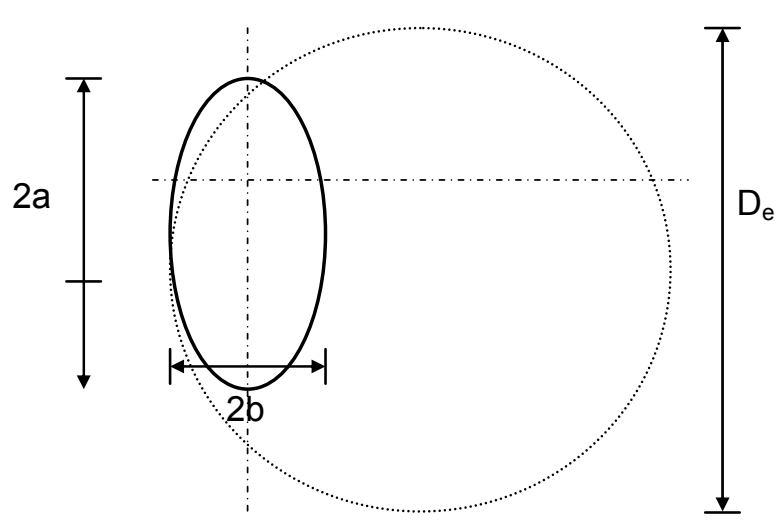

Figure 25. Illustration of equivalent diameter

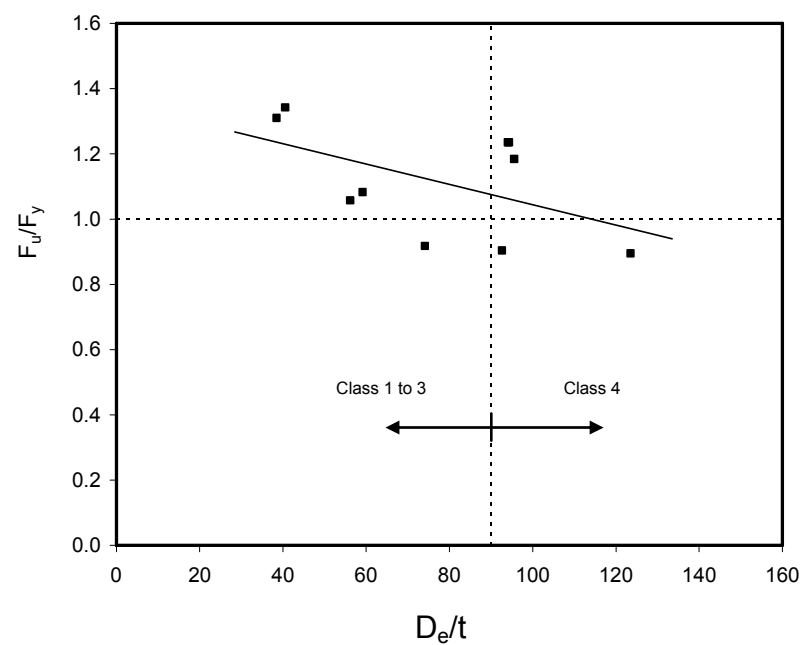

Figure 26. Normalised compressive resistance versus cross-section slenderness

It may be observed from Table 12 and Figure 26 that the three OHS 300x150x8.0 stub columns have performed better than expected, with the $F_{u} / F_{y}$ values (of around 1.2) indicating a high degree of strain hardening. However, inspection of the load-end shortening curves of Figure 10 does not support this result and the high values of $F_{u} / F_{y}$ are believed to be due to normalisation of the ultimate stub column load in compression by the yield load in tension, and assuming symmetrical stress-strain behaviour in tension and compression. Normalisation could alternatively be made against the stub column stress-strain curve itself or against compressive coupon data. Normalisation against the stub column curve itself is generally inappropriate since the material behaviour is influenced by the effects of local buckling (which may preclude reaching yield), initial imperfections and residual stresses. Normalisation against the compressive stress-strain curve is preferable and this will be generated as part of future studies. The finite element models of the stub columns are based on tensile properties and this issue therefore does not arise. 
Results of the nine tested beams and six modelled beams (generated as part of the parametric finite element study and shown in Figure 24) are presented in Figure 27. The ultimate moments attained in the tests (or FE models) $\mathrm{M}_{\mathrm{u}}$ have been normalised against the plastic moment resistances $\mathrm{M}_{\mathrm{pl}}$ (calculated as the plastic modulus multiplied by the material yield strength) and plotted against cross-section slenderness $\mathrm{D}_{\mathrm{e}} / \mathrm{t} \varepsilon^{2}$ in Figure 27, where the section classification limits are also included. In bending, Class 1 cross-sections are capable of reaching and maintaining their full plastic moment (and may therefore be used in plastic design). Class 2 cross-sections are also capable of reaching their full plastic moment in bending but have a somewhat lower deformation capacity. In Class 3 cross-sections local buckling prevents attainment of the full plastic moment and the bending moment resistance is therefore limited to the (elastic) yield moment. For Class 4 cross-sections, local buckling occurs in the elastic range for which an effective cross-section is defined based on the width-to-thickness (or diameter-to-thickness) ratios of constituent elements, and this is used to determine the cross-sectional bending resistance.

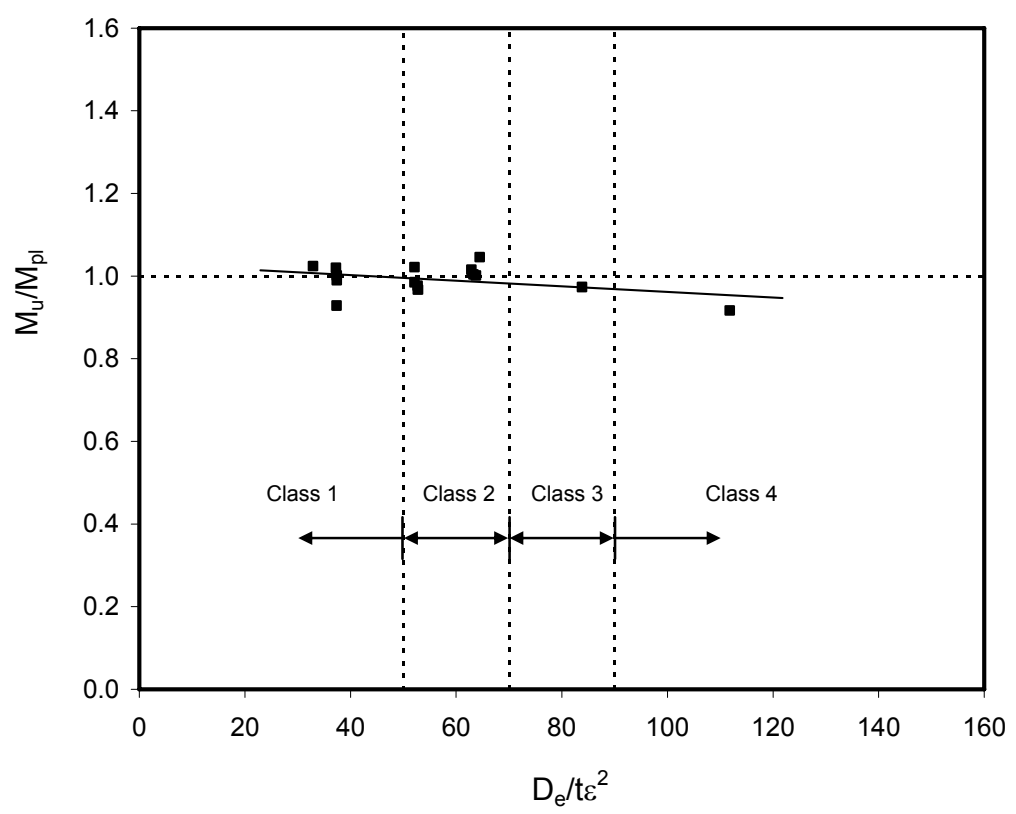

Figure 27. Normalised bending resistance versus cross-section slenderness

From Figure 27, the anticipated trend of decreasing moment resistance with increasing crosssection slenderness may be observed. The proposed classification limits are broadly acceptable, though some of the Class 1 and 2 cross-sections have not performed as would be expected - this apparent under-performance may be associated with the normalisation method (as discussed above) or variation in geometric properties. The classification limits will be reviewed on the basis of the results of further testing and finite element modelling which is currently underway.

\section{CONCLUSIONS}

This paper has provided an introduction to the behaviour of structural oval hollow sections and described a series of material and cross-section tests conducted at Imperial College London. In total 7 stub column tests and 7 tensile coupon tests were conducted. Further tests carried out in minor axis bending at the University of Southampton have also been summarised and reviewed. For all tests, measured geometry and material properties have been tabulated and the key results summarised. Full load-deformation curves for each test have been provided.

In parallel to the testing, a numerical modelling programme using the finite element package ABAQUS has been carried out. For stub column behaviour, ultimate load was generally well 
predicted, but deformation at ultimate load was not well predicted. For bending behaviour, the full bending moment-deformation history was consistently well predicted. Parametric studies were performed to investigate the influence of cross-section slenderness on structural response, where both strain hardening and local buckling effects were observed.

The test and finite element results have been compared with preliminary rules for section classification of oval hollow sections. The classification limits have been shown to be broadly acceptable, but require further test and finite element results for a thorough validation. Such data are currently being generated.

\section{ACKNOWLEDGEMENTS}

The author would like to thank Corus for the supply of test specimens and for funding contributions, and Eddie Hole (Corus Tubes) and Ken Chan (Imperial College London) for their technical input.

\section{REFERENCES}

[1] Gardner, L., "Structural behaviour of oval hollow sections", Proceedings of the Fourth International Conference on Advances in Steel Structures. 13th-15th June, 2005, Shanghai, China, 2005, pp.517-522.

[2] Gardner, L. and Ministro, A., "Structural steel oval hollow sections", The Structural Engineer, 2005, 83(21), pp.32-36.

[3] Marguerre, K., "Stability of cylindrical shells of variable curvature", NACA TM 1302, 1951.

[4] prEN 10210-2, "Hot finished structural hollow sections of non-alloy and fine grain steels Part 2: Tolerances, dimensions and sectional properties", CEN, 2003.

[5] Hutchinson, J.W., "Buckling and initial post-buckling behaviour of oval cylindrical shells under axial compression", Transactions of the American Society of Mechanical Engineers, Journal of Applied Mechanics, March 1968, pp.66-72.

[6] Feinstein, G., Erickson, B. and Kempner, J., "Stability of oval cylindrical shells: Experimental investigation of initial and ultimate buckling loads of fixed-end, oval cylindrical shells under axial compression", Experimental Mechanics, November 1971, pp.514-520.

[7] Tennyson, R.C., Booton, M. and Caswell, R.D., "Buckling of imperfect elliptical cylindrical shells under axial compression", American Institute of Aeronautics and Astronautics Journal, 1971, 9(2), pp.250-255.

[8] The Steel Construction Institute, "Gross section properties of elliptical hollow sections", The Steel Construction Institute, UK, 2003.

[9] Corus Tubes, “Celsius 355® Ovals - Sizes and Resistances, Eurocode Version”, Structural and Conveyance Publication, Corus, 2003.

[10] Kempner, J., "Some results on buckling and post-buckling of cylindrical shells", Collected papers on Instability of Shell Structures, NASA TN D-1510, 1962, pp.173-186.

[11] Kempner, J. and Chen, Y.N., "Large deflections of an axially compressed oval cylindrical shell”, Proceedings of the Eleventh International Congress of Applied Mechanics, Munich, Springer-Verlag, Berlin, 1964, pp.299-305. 
[12] Donnell, L.H., "A new theory for the buckling of thin cylinders under axial compression and bending", Transactions of the American Society of Mechanical Engineers, 1934, 56, pp.795-806.

[13] Kempner, J. and Chen, Y.N., "Postbuckling of an axially compressed oval cylindrical shell", Proceedings of the Twelth International Congress of Applied Mechanics, Stanford University, 1968, pp.246-256.

[14] Koroleva, E., "Stability of cylindrical shells of oval cross-section in the bending stressstate", Prikladnaya Matematika i Mekhanika, 1974, 37(5), pp.901-904.

[15] Kempner, J. and Chen, Y.N., "Buckling and initial postbuckling of oval cylindrical shells under combined axial compression and bending", Transactions of the New York Academy of Sciences, 1974, 36(2), pp.171-191.

[16] Chen, Y.N. and Kempner, J., "Buckling of oval cylindrical shells under compression and asymmetric bending", AIAA Journal, 1976, 14(9), pp.1235-1240.

[17] Tvergaard, V., "Buckling of elastic-plastic oval cylindrical shells under axial compression" International Journal of Solids and Structures, 1976, 12(9-10), pp.683-691.

[18] Tang, S.C., Chu, C.C. and Yeung, K.S., "Collapse of long, noncircular, cylindrical shells under pure bending”, Computers and Structures, 1985, 21(6), pp.1345-1353.

[19] EN 10002-1, "Metallic materials - Tensile testing - Part 1: Method of test at ambient temperature", CEN, 2001.

[20] Gardner, L. and Ministro, A., "Testing and numerical modelling of structural steel oval hollow sections", Research Report No. 04-002-ST, Department of Civil and Environmental Engineering, Imperial College London, 2004.

[21] Schafer, B. and Peköz, T., "Computational modelling of cold-formed steel: characterizing geometric imperfections and residual imperfections", Journal of Constructional Steel Research, 1998, 47(3), pp.193-210.

[22] Gardner, L. and Nethercot, D.A., "Experiments on stainless steel hollow sections - Part 1: Material and cross-sectional behaviour", Journal of Constructional Steel Research, 2004, 60(9), pp.1291-1318.

[23] Eckhardt, C., "Classification of oval hollow sections", School of Civil Engineering Report, University of Southampton, 2004.

[24] ABAQUS, “ABAQUS/ Standard User's Manual Volumes I-III and ABAQUS CAE Manual", Version 6.4, Hibbitt, Karlsson \& Sorensen, Inc. Pawtucket, USA, 2003.

[25] prEN 1993-1-1, "Eurocode 3: Design of steel structures - Part 1.1: General rules and rules for buildings", CEN, 2003.

[26] Gardner, L. and Nethercot, D.A., "Designers' Guide to EN 1993-1-1: Eurocode 3: Design of Steel Structures", Thomas Telford Publishing, London, 2005. 